Article

\title{
A Feature-Based Cost Estimation Model for Wind Turbine Blade Spar Caps
}

\author{
J. Clarke ${ }^{1, *}$, A. McIlhagger ${ }^{1}$, E. Archer ${ }^{1}$, T. Dooher ${ }^{1}$, T. Flanagan ${ }^{2}$ and P. Schubel $^{3}$ \\ 1 Engineering Composites Research Centre, Ulster University, Jordanstown BT37 0QB, UK; \\ a.mcilhagger@ulster.ac.uk (A.M.); e.archer@ulster.ac.uk (E.A.); t.dooher@ulster.ac.uk (T.D.) \\ 2 Éire Composites Teo, An Choill Rua, H91Y923 Indreabhán, Ireland; t.flanagan@eirecomposites.com \\ 3 Institute of Advanced Engineering and Space Sciences, University of Southern Queensland, \\ Toowoomba Qld 4350, Australia; peter.schubel@usq.edu.au \\ * Correspondence: clarkej-24@ulster.ac.uk
}

Received: 11 February 2020; Accepted: 24 March 2020; Published: 30 March 2020

\begin{abstract}
A problem for wind turbine operators is decreasing prices for wind-generated electricity. Many turbines are approaching their rated 20-year lives. A more economically viable and sustainable solution that reduces Levelized Cost of Energy (LCOE) and avoids expensive turbine replacement is retrofitting new spar caps blades. A new cost model assesses the feasibility of retrofitting 35 to 75 $m$ turbines with GFRP (glass fiber reinforced polymer composite) and longer length CFRP (carbon fiber reinforced composite) spar caps. Spar cap cost scales with features such as mass, volume fraction and complexity. Organizational learning is a cost factor. Material and direct labor increase as proportions of total cost while tooling, capital, utilities, and indirect labor decrease. There is good agreement between a manufacturer and the model. Twenty-year turbines were compared with retrofitted spar caps over 25 years for LCOE. Same length GFRP and longer length CFRP spar cap retrofits decrease LCOE. Longer length CFRP spar caps decrease LCOE compared with GFRP retrofits over 25 years. CFRP material cost impacts CFRP retrofit feasibility. Retrofitted turbines must meet engineering, operational performance, and planning requirements criteria. Software algorithms may improve human learning and enable automatic updates from varying design and cost inputs, thereby increasing cost prediction accuracy.
\end{abstract}

Keywords: Spar cap; complexity; features; cost model; data constraints; organizational learning

\section{Introduction}

A major problem for wind turbine operators is that electricity prices are predicted to fall from $£ 0.078 / \mathrm{kWh}$ in 2014 to $£ 0.045 / \mathrm{kWh}$ by 2020, thereby impacting the economic feasibility of wind turbine projects [1]. A system-level design involving rotor, blades and tower is very expensive, so a possible solution is retrofitting existing turbine designs with longer length carbon fiber reinforced composite (CFRP) spar cap blades [2] for increased electricity generation [3] and lower Levelized Cost of Energy (LCOE) [4].

Another issue is resource sustainability, as wind turbines produce low carbon energy but contain large amounts of materials. Turbine life extension by blade replacement/retrofit is a potential strategy for maximizing resource effectiveness [5]. Turbines below $1 \mathrm{MW}$ are now either approaching or exceeding their rated design lives of 20 years, while many energy generating classes of turbine from 1 to $6 \mathrm{MW}$ are over 10 years old [6]. Blades are considered to wear out the fastest compared with other turbine components, therefore life extension by retrofitting new blades is a route to maximize resource effectiveness [7]. However, if blade retrofitting is to become widely adopted as a strategy for reducing LCOE and maximizing resource effectiveness, retrofitted blades must perform within the same design 
and operational constraints as before in terms of wind loading regimes, allowable fatigue, permitted blade deflection, and required electricity generation.

The research objective of this study was to develop a cost model for assessing the economic feasibility, in terms of LCOE, of replacing spar cap blades in the 35 to $75 \mathrm{~m}$ range with new spar cap blades of the same or longer lengths. The model will focus on how part features and production rate affect resource costs such as tooling, capital, labor, and electricity, and is intended to be used concurrently with blade design so that retrofitted blades meet existing engineering and operational power generation performance criteria. A key issue was unavailability of certain cost data so a resource-based technical cost model (TCM) approach was employed. The model is capable of improvement in predictive power as more data becomes available. A novel expression is introduced relating manufacturing complexity and organizational learning as cost factors.

The model will compare three scenarios for LCOE:

- LCOE for turbines with glass fiber reinforced polymer composite (GFRP) blades from 35 to $75 \mathrm{~m}$ for 20 years, with no blade retrofits.

- LCOE for 25 years: retrofitted GFRP blades installed at 20 years with a 5-year extension.

- LCOE for 25 years: retrofitted longer length CFRP blades installed at 20 years with a 5 -year extension.

The feature-based model was derived from resource cost equations derived by Ashby [8]. Available cost data was kindly provided by a spar cap manufacturing company [9]. The co-authors of this study provided valuable insights and ideas while one co-author (Dooher) suggested an algorithm that automatically calculates various constants from cost data in order to enhance the methodologies underlying the model, thereby improving model effectiveness.

\section{Literature Review}

\subsection{Wind Turbine Cost Models}

Table 1 compares existing wind turbine cost models and their key attributes with the proposed model and its key attributes. Two models from Sandia address how material, tooling, capital, and labor costs scale as a function of blade radius for 30, 40, 50, 70 and 100 m blades $[9,10]$. The US National Renewable Energy Laboratory (NREL) [11,12], developed cost models for the entire turbine, including tower, hub, gearbox, foundation, and rotor blades. Schubel [13,14] and Hutchinson et al. [15] employed technical cost modelling (TCM) to compare hand-lay, prepreg, vacuum infusion, and resin transfer molding with automated manufacturing techniques for a $40 \mathrm{~m}$ and $45 \mathrm{~m}$ wind turbine blade. Murray et al. [16] employed a techno-economic model to estimate the cost of a thermoplastic turbine blade relative to a baseline thermoset epoxy blade and supplied costs for epoxy resin, and glass and carbon fiber that were used in this study.

Table 1. Comparison of existing wind turbine cost models with the proposed cost model.

\begin{tabular}{cc}
\hline Existing Cost Models & Key Attributes of existing Cost Model \\
\hline $\begin{array}{c}\text { Sandia Large Blade Manufacturing Cost Study for } 40 \mathrm{~m} \\
\text { and } 100 \mathrm{~m} \text { Blades [9,10] }\end{array}$ & $\begin{array}{c}\text { Costs for a } 40 \mathrm{~m} \text { blade, scaling factor derived to estimate } \\
\text { costs for a } 100 \mathrm{~m} \text { blade. Special emphasis on labor costs }\end{array}$ \\
\hline US National Renewable Energy Laboratory (NREL) [11,12] & $\begin{array}{c}\text { Cost for entire turbine. Cost scaling as function of blade } \\
\text { radius. }\end{array}$ \\
\hline Schubel [13] & $\begin{array}{c}\text { Technical cost model for a } 40 \text { m blade. Compare cost of } \\
\text { traditional manufacturing methods with automated } \\
\text { manufacturing costs }\end{array}$ \\
\hline
\end{tabular}


Table 1. Cont.

\begin{tabular}{|c|c|}
\hline Existing Cost Models & Key Attributes of existing Cost Model \\
\hline Schubel [14] & $\begin{array}{l}\text { Technical cost modelling for a generic } 45 \mathrm{~m} \text { turbine blade } \\
\text { manufactured using vacuum infusion. }\end{array}$ \\
\hline Hutchinson et al. [15] & $\begin{array}{l}\text { Technical cost model compares liquid resin transfer } \\
\text { molding with vacuum infusion for a generic } 40 \mathrm{~m} \text { blade. }\end{array}$ \\
\hline Murray et al. [16] & $\begin{array}{l}\text { A techno-economic model for estimating the cost of a } \\
\text { thermoplastic wind turbine blade relative to a baseline } \\
\text { thermoset epoxy blade }\end{array}$ \\
\hline Proposed Cost Model & Key Attributes of proposed Cost Model \\
\hline $\begin{array}{l}\text { Technical cost model to calculate cost of wind turbine spar } \\
\text { caps from } 35 \text { to } 75 \mathrm{~m} \text { in length. } \\
\text { Assess economic feasibility, in terms of LCOE, of blade } \\
\text { retrofits for wind turbine life extensions by } \\
\text { - } \quad \text { comparing LCOE for 20-year turbine life with LCOE for } \\
\text { extended turbine life } \\
\text { - comparing LCOE for same length GFRP retrofits with } \\
\text { LCOE for longer length CFRP retrofits } \\
\text { Cost data for a } 35 \text { m spar cap: tooling, capital, labor, } \\
\text { and utilities. } \\
\text { Mass data for spar cap lengths } 35,40,45,50,55,60,65,70 \text {, } \\
75 \mathrm{~m} .\end{array}$ & $\begin{array}{c}\text { A relationship that scales the cost of spar cap blade lengths } \\
\text { from } 35 \text { to } 75 \text { m with Spar Cap features: mass, complexity, } \\
\text { and volume fraction } \\
\text { Two cost curves, one for CFRP and one for GFRP, in spar } \\
\text { caps from } 35 \text { to } 75 \text { m in length } \\
\text { Capability to model scenarios for LCOE with varying } \\
\text { inputs, e.g., material cost, capacity factor. } \\
\text { A novel relationship between manufacturing complexity } \\
\text { and organizational learning }\end{array}$ \\
\hline
\end{tabular}

\subsection{Manufacturing Cost Models}

Esawi [17] provides a comprehensive summary of manufacturing cost model approaches. Function-costing or parametric methods extrapolate the cost of a part that is a variant of an existing family for which historic cost data already exist. Activity-based costing methods calculate and sum the cost of each unit operation involved in the manufacture of a part but requires a large amount of pre-existing input data. Resource-based modelling accounts for materials, energy, capital, time, and information resources and is approximate, as values for these inputs are often unknown. Technical cost modelling (TCM) includes sub-models for how equipment, tooling cost, and production rate scale with part features such as part mass, size, and complexity. Part cost increases with increasing complexity while production rate decreases with complexity. As more data becomes available, detail can be added to a TCM model to improve predictive power.

Manufacturing complexity is a cost [18]. A complex system is one with many parts whose relationships are not simple $[19,20]$. Complexity does not exist where there is either complete order or complete disorder [21]. All the elements in completely disordered systems act in unpredictable ways. Complex manufacturing systems exist only when there are ordered relationships between the elements in the system. Therefore, complexity exists in manufacturing systems that are on the continuum between complete disorder and total order [22]. Systems with higher complexity have more problems than systems with lower complexity, implying higher cost. Therefore, by measuring the system's complexity, system problems can be identified and remedied, thereby lowering system cost [23]. Martinez-Garcia et al. [24] derived a method for developing a virtual human interface for reinforcing acquired learning based on the characteristics of human memory patterns.

Volume fraction plays a dominant role in composites manufacturing due to prepreg geometrical heterogeneities, while significant permeability variation during impregnation/consolidation results in flow-induced voids and resin rich zones. A higher fiber volume fraction causes increased scrap and therefore increased cost [25]. Adenkunle et al. [26-28] defined complexity as the number of part features, for example dimensions, holes, straight lines, circles, or components in a part.

The choice of manufacturing cost model will be constrained by the available cost data. The only data available for this study were tooling and capital costs supplied by a spar cap manufacturer [29] for a $10 \mathrm{~m}$ rectangular shape spar cap analogue termed a Reference Standard; tooling, capital, labor, and electrical power cost data for a $35 \mathrm{~m}$ blade spar cap from the Wind Energy Handbook [30], termed 
a baseline Calibration Standard; production rates for the $10 \mathrm{~m}$ analogue and $35 \mathrm{~m}$ spar cap; and glass and carbon composite masses for spar caps with a box spar design in the 35 to 75 m blade range [31], in which the mass of unidirectional GFRP and CFRP composite required for each spar cap length is specified for allowable tip deflections in a given wind loading regime.

Loch et al. [32] emphasise that engineering studies should be carried out concurrently with financial modelling for optimised cost-effective design. If retrofitted blades can meet given wind loading, tip deflection, and power generation performance criteria, while comparing extra power generation with longer blades against power reduction with increased turbulence, blade retrofitting scenarios can be modelled that extend the useful life of a wind turbine by reducing LCOE compared to LCOE for a 20-year life baseline and complete turbine replacement, thereby improving material efficiency and sustainability

Boyle [33] describes a typical wind speed distribution plot. Turbine capital cost and operational and maintenance $(\mathrm{O}$ and $\mathrm{M})$ data were taken from studies by the International Renewable Energy Agency [1] and the US National Renewable Energy Laboratory [34]. Grant-Thornton [35] provides a succinct description of the discount rate or cost of capital, termed the weighted average cost of capital (WACC), which is the cost of debt, the equity premium of the investors, and the share of debt and equity in the project. The discount rate is a measure of risk that will be charged by investors based on whether wind generation is offshore (higher rate) or onshore (lower rate) and location by country. Based on survey results from worldwide onshore and offshore locations, a rate of $7 \%$ was chosen for this study, which is the average rate for Europe and North America between onshore and offshore wind generation.

Saad [36] describes how in any iteration methods, a reasonable "guess" can be assumed for one or more unknown variables. Iterative methods are often the only choice for non-linear equations where powers $x, y$ and $z$ are unknown. Denn [37] describes similar methods for use in engineering when extensive data is unavailable, for example, estimating the number of stages required for a complete solvent extraction process in chemical engineering. Lemon [38] and Bloomfield [39] point out that in any industrial cost modelling scenario for new product development, cost estimates or "Rough Order of Magnitude" variations up to $20 \%$ are acceptable.

\subsection{Material Efficiency and Turbine Life Extension by Blade Retrofit}

Allwood et al. [40] point out that global stocks for most materials are enough to meet anticipated demand for buildings, infrastructure, equipment, and products, but that environmental impacts of materials production and processing, particularly those related to energy, are becoming critical. These impacts can be mitigated by process efficiencies, but the increase in overall impacts will be unacceptable unless material production and processing is reduced through longer-lasting products, modularization and remanufacturing, component re-use, and designing products with less material.

Jensen [41] noted that wind turbines produce low carbon energy but contain large amounts of materials. For maximum resource effectiveness, strategies should be adopted for extending the lifetime of wind turbines, including retrofitting same length blades to restore output or longer blades made from carbon/glass hybrids to increase output. A refurbished wind turbine must have the same performance in terms of engineering specifications and power generation that the turbine had before refurbishment. Turbine lifetime is also determined by other factors, while economic lifetime is often shorter than technical lifetime.

Boccard [42] defined the capacity factor as the ratio of electricity produced by a turbine over a period divided by the amount of output produced had it operated at full nameplate capacity for the same period. The capacity factor must be at a certain minimum level for wind turbines to operate feasibly. Boccard observed mean values below $21 \%$ in 2009 [42], while more recent observed values are between $37 \%$ and $40 \%$ [43]. Staffell and Green [44] observed that various issues can affect the capacity factor, for example, turbine downtime, which can result in a $4-7 \%$ fall in output. Hughes [45] noted that the capacity factor declines significantly as the turbine ages, with declines of $0.9 \%$ per year for 
the first 10 years of operation from a starting point of $24 \%$ to $11 \%$ in year 15 . Staffell and Green [44] observed a decline of $0.45 \%$ per year and noted a decline rate two to three times higher for turbines built before 2003. McKinsey [46] found that performance is adversely affected by dirty or pitted blades. Maxey [47] observed that General Electric (2014) replaced $77 \mathrm{~m}$ blades with a $91 \mathrm{~m}$ retrofit, boosting annual electricity production by $20 \%$.

\subsection{Blade Design and Operational Performance}

In a turbine blade, the spar is the principal blade component and carries $85-90 \%$ of the bending load acting on the blade. Spars and internal webs in the blades are used to restrict the effect of flapwise bending loads, while the blade profile trailing edges carry edgewise bending loads. Gurit, Roth-Johnson, $\mathrm{Wu}$, and Singh provide comprehensive reviews of wind turbine blade structural design [31,48-50]. Where GFRP blades replace GFRP blades having the same design and mechanical properties, there should be no additional design issues for the retrofit blades. The hub, pitch mechanism, bearings, spinner, nose, shaft, and gearbox of the turbine are designed to carry a given blade load for a rated maximum wind speed. Where lighter, longer, thinner, and higher modulus $\mathrm{S}$ glass, $\mathrm{R}$ glass, or CFRP blades are being considered as replacements for lower modulus shorter E-glass blades, the modifications required for the hub, pitch mechanism, bearings, spinner, nose, shaft, and gearbox when subjected to a lower load regime should be assessed in addition to operational, safety, and performance issues.

A retrofitted blade must be specified for a given wind loading regime and have a maximum allowable tip deflection to avoid tower strikes so that power generation performance targets are met. The following engineering parameters are key for optimised turbine blade performance: natural frequency, wind loading, blade tip deflection, aerodynamic efficiency, and edgewise fatigue loading. Large blade design can be driven by the requirement to maintain a high natural frequency so that resonance caused by the pressure drop as the blade passes the tower is avoided. However, above approximately $45 \mathrm{~m}$ to $50 \mathrm{~m}$ blade length, the design becomes dominated by tip deflection and maintaining tower clearance. A solution is to increase stiffness by adding more unidirectional GFRP in the spar cap as the prinicpal load bearing component, but this is not ideal as the glass has to be added further and further away from the outer surface resulting in a thicker, less aerodynamically efficient design. Furthermore, additional glass increases blade weight, thereby increasing fatigue loads in the edgewise direction. The edgewise fatigue loads are caused by the weight of the blade creating bending firstly in one direction as it climbs to the highest point above the nacelle, and then reversed loading as the blade heads back towards the ground.

Higher modulus glass fiber materials, such as E-glass prepreg, R-glass, and S-Glass permit thinner sections, thereby increasing aerodynamic efficiency. A high modulus glass (92 GPa) prepreg will enable a $5-10 \%$ increase in blade length for the same blade mass. However, longer blades with glass spar caps require more trailing edge and/or shell laminate to deal with increasing edgewise fatigue loads, resulting in increased weight, loss of aerofoil efficiency, and increased edgewise loading. As CFRP spar caps have higher stiffness and strength-to-weight ratios compared with E-glass GFRP, a CFRP solution results in longer, thinner, more efficient blades leading to more energy capture and a lower overall LCOE compared to an equivalent GFRP blade of the same weight [35]. However, compared with GFRP, CFRP has relatively lower damage tolerance and lower compressive strength than CFRP. Sharma [51] oberved that although CFRP is becoming cost competitive with GFRP, CFRP remains much more expensive than GFRP, so the economic advantages of a CFRP spar cap do not generally transfer to other parts of the blade, as strength rather than stiffness is the key criterion and the weight penalty of glass becomes less signifiant. Therefore, the optimal compromise in terms of performance, loading, and cost is to use CFRP in the spar cap for maximum stiffness and E-glass GFRP in the outer periphery for maximium strength.

If CFRP spar caps are to be interfaced structurally with glass laminate, thermally-induced stresses caused by the difference in coefficient of thermal expansion (CTE) of the two materials is a likely 
outcome. In general, blades built using the same material for all the components (spar, webs, shell) will see much smaller thermal stresses than those built with glass shell and webs, and a carbon spar cap. Thermally induced stress as an additional load case is often the key aspect for structural blade designers when considering a CFRP solution. This is most noticeable when materials with a significant difference in CTE are combined, for example, at the interface between the glass biaxial shear web and the carbon unidirectional spar cap where the difference in CTE is one order of magnitude. Longer CFRP blades will be more prone to lightning strike damage so the cost implications of protection must be balanced against increased power generation from a longer, more efficient blade. The general trend for larger rotor blades, particularly offshore where the uppermost blade tip may be $150 \mathrm{~m}$ above sea level, is to use metal meshes or surface treatments to make the surface conductive.

Wind farms are affected by increased turbulence with output falling between $5 \%$ and $15 \%$ [52], while longer retrofits will increase inter-turbine turbulence. Attias and Ladany [52] derived a model that calculated the optimum layout of a wind turbine farm that maximizes net present value and the internal rate of return in terms of a compromise between electricity output and inter-turbine turbulence. Using data from several studies, Ortegon et al. [53] stated that the life of a refurbished turbine could be extended by six years.

\section{Cost Model Methodology, Selection of Cost Modelling Approach}

An Excel-based cost model was developed to derive a cost curve of spar cap cost versus spar cap blade length from 35 to $75 \mathrm{~m}$ in order to estimate the cost of GFRP and CFRP retrofit spar cap blades. The model is intended as a tool for assessing the economic feasibility of retrofitting wind turbine blades (Figure 1). The life extension for this model is five years. If the cost of the CFRP and GFRP retrofits are known in addition to turbine investment, operational, and maintenance costs, the Levelized Cost of Energy (LCOE) for these retrofits over a 25-year extended life can be compared with each other and with LCOE for 20-year baseline GFRP turbine blades. CFRP retrofits were $3 \mathrm{~m}$ longer than the replaced blade. For example, a $38 \mathrm{~m}$ blade replaces a $35 \mathrm{~m}$ blade, a $48 \mathrm{~m}$ blade replaces a $45 \mathrm{~m}$ blade, and so on. Longer length CFRP retrofits were not considered due to likely turbulence effects and planning restrictions. GFRP retrofits will have the same length as replaced GFRP turbine blades.

A resource-based technical cost modelling approach, in which historical cost data is either not available or does not exist, was used to derive a cost curve for lengths 40 to $75 \mathrm{~m}$. Spar cap manufacturing resources are material, tooling, capital (plant infrastructure), direct and indirect labor, and utilities. Material for each spar cap length was already known. Indirect labor costs are for management and administration. Utilities are electricity costs. Both indirect labor and utilities costs are assumed to vary only with the production rate over the 35 to $75 \mathrm{~m}$ range. Tooling, capital, and direct labor costs for 40 to $75 \mathrm{~m}$ were unavailable. Employing available tooling, capital, and direct labor cost data, technical cost modelling was used to develop a Cost Scaling Feature Factor in which tooling, capital, and direct labor costs scale with spar cap features defined as mass, volume fraction, and complexity. The production rate will determine cost per part: the higher the rate, the lower the cost per part. Based on the known production rate for the $35 \mathrm{~m}$ spar cap, and assuming the production rate decreases with spar cap mass, volume fraction, and complexity, the Cost Scaling Feature Factor can estimate production rates for the 40 to $75 \mathrm{~m}$ range. As more data becomes available, detail can be added to the model to improve predictive power.

From estimated cost data, a cost curve was plotted for spar cap cost against blade length. For validation, the curve was compared with one independently derived by a $35 \mathrm{~m}$ wind turbine blade manufacturer for a box spar turbine blade design in 35 to $75 \mathrm{~m}$ blade lengths. For each blade length, CFRP 3 m extended length retrofit costs and GFRP retrofit costs were derived from the cost curve. Retrofit costs, model-generated turbine investment costs, operation and maintenance costs, and power generation data were used to find the Levelized Cost of Energy (LCOE) at 25 years for retrofitted CFRP and GFRP blades, which was then compared with each other and with LCOE for a GFRP 20-year 
baseline. To account for the effect of higher GFRP mass on Direct Labor cost, embedded learning as a measure of manufacturing complexity was investigated as a cost factor.

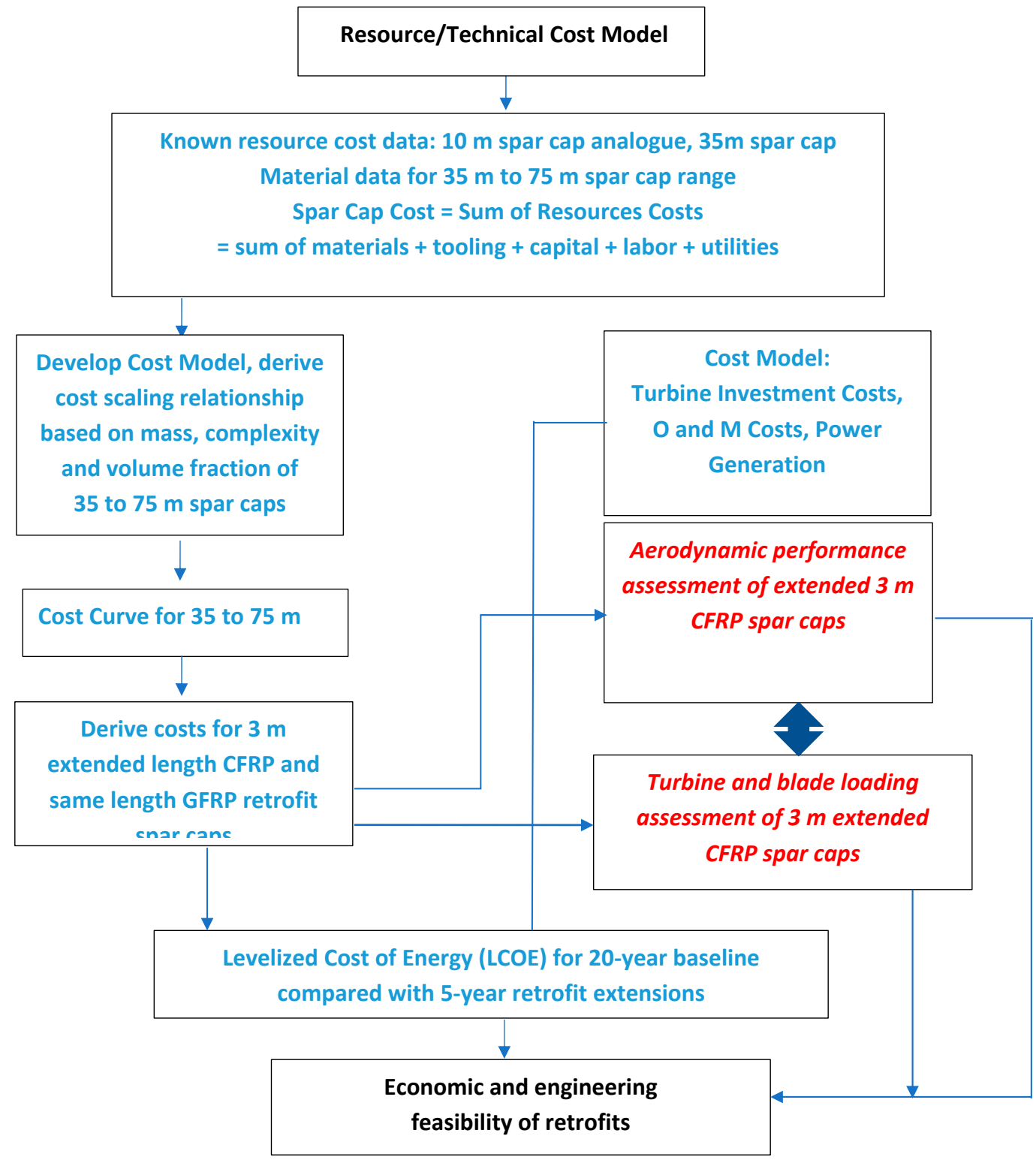

Figure 1. Integrated cost model for finanacial and engineering assessment of spar cap retrofits.

\subsection{Development of a Resource-Based, Technical Cost Model}

The model is a linked series of Excel spreadsheets developed from a framework for pre-selecting manufacturing processes. Manufacturing cost $(\mathrm{mc})$ is the sum of resource costs, i.e., material cost for one spar cap, tooling cost, capital cost, and overheads (labor and utilities).

Spar cap cost $=$ material + tooling + capital + labor + utility resource costs

$$
C_{m c}=\frac{m C_{m}}{(1-f)}+\frac{C_{t}}{n}\left(1+\frac{n_{r}}{n_{t}}\right)+\frac{1}{n_{r}}\left(\frac{C_{c}}{L t_{w o}}+C_{o h}\right)
$$


Each of five spreadsheets corresponds to a resource cost. Two other spreadsheets correspond to production rate and cost per part. From this data, a cost curve was derived for the 35 to $75 \mathrm{~m}$ spar cap range, from which cost data for retrofit spar caps was taken for LCOE calculations. The last spreadsheet calculates levelized cost of energy (LCOE) from retrofit spar cap costs, turbine investment costs, discounted operational and maintenance costs $(\mathrm{O}$ and $\mathrm{M})$, and power generation for each blade length from 35 to $75 \mathrm{~m}$, including longer length CFRP retrofit blades. Levelized Cost of Energy (LCOE) is defined as:

$$
\mathrm{LCOE}=\sum_{t=1}^{n} \frac{I_{t}+M_{t}+F_{t}}{(1+r)^{t}} / \sum_{t=1}^{n} \frac{E_{t}}{(1+r)^{t}}
$$

where:

$I_{t}=$ Investment expenditures in year $t$ (including financing);

$M_{t}=$ Operations and maintenance expenditures in year $t$;

$F_{t}=$ Fuel expenditures in year $\mathrm{t}, E_{t}=$ Electrical power generation in year $\mathrm{t}$;

$r=$ Discount rate.

LCOE is a lifetime cost per kWh in which costs and energy generation are discounted to today's values or net present value. Fuel costs are zero for wind generated energy, so $F_{t}=0$. Initial investment $I_{t}$ is the turbine capital cost in year 0 and additional investment cost can be a turbine retrofit in a given year $t$. Electrical power generated from a wind turbine blade was calculated from Equation (3) and a wind speed distribution plot (Figure 2).

$$
\text { Power }=1 / 2 C A \rho v^{3}
$$

where:

$C=$ Capacity Factor, $A=$ area swept by turbine blade $=\pi r^{2}$;

$r=$ radius/turbine blade length, $\rho=$ air density, $v=$ wind speed.

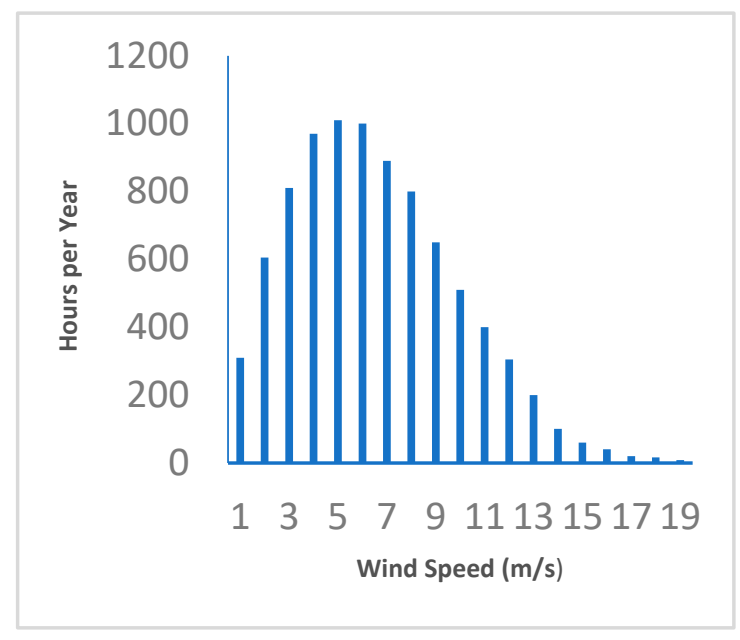

Figure 2. A wind speed distribution plot [33].

\subsection{Available Resource Cost Data}

The mass of each spar cap from 35 to $75 \mathrm{~m}$ was calculated [31] for a given wind loading regime, allowable tip deflection, and edge fatigue. Figure 3 shows the variation of spar cap CFRP and GFRP masses with length and is a polynomial quadratic function. Tooling, capital, labor, utilities, and fiber and resin costs are shown in Tables 2 and 3. 


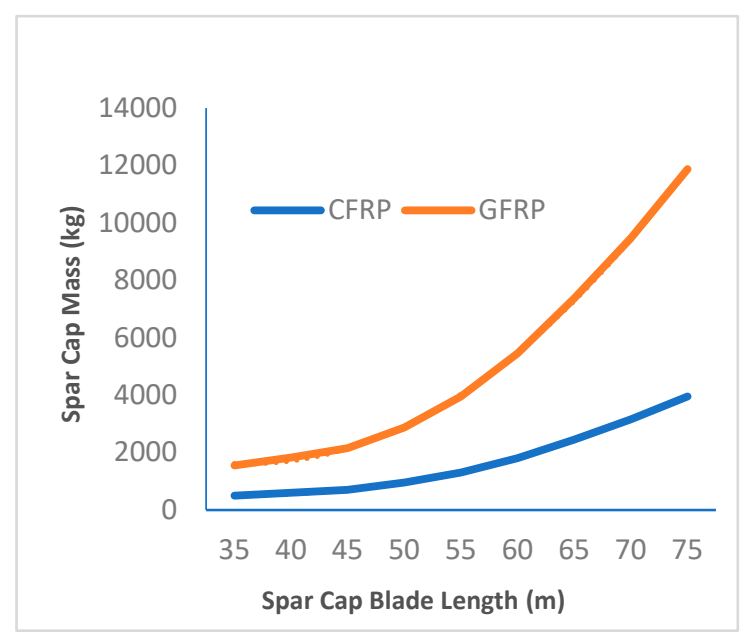

Figure 3. Spar cap mass with blade length [31].

Table 2. Data for Reference Standard: 10 m spar cap analogue [29].

\begin{tabular}{ccc}
\hline Tooling Cost & Capital Cost & Annual Production Rate \\
\hline$£ 20,000$ & $£ 227,500$ & 300 approx. \\
\hline
\end{tabular}

Table 3. Calibration Standard: $35 \mathrm{~m}$ spar cap baseline calibration standard [29,30].

\begin{tabular}{cc}
\hline Resource & Cost \\
\hline Tooling cost of one mold tool & $£ 240,000-£ 292,000$ \\
Capital Cost for one mold tool & $£ 1,750,000-£ 2,200,000$ \\
Direct Labor & $£ 23 / \mathrm{hour}$ \\
Indirect Labor per year & $£ 600,600$ \\
Utilities, electricity per year & $£ 428,640$ \\
Cost of unidirectional carbon fiber & $£ 31 / \mathrm{kg}$ \\
Cost of epoxy resin & $£ 3 / \mathrm{kg}$ \\
Cost of UD E-glass fiber & $£ 3 / \mathrm{kg}$ \\
\hline
\end{tabular}

Fringe factors, such as interest rate on capital, machine residual value, insurance, and labor bonuses are assumed. For commercial sensitivity reasons, Tooling and Capital Costs were supplied as ranges, so mid-range values were selected. Capital Cost is for building infrastructure and manufacturing costs for one spar cap production line.

\subsection{Technical Cost Modelling: Tooling, Capital, Labor, Production Rate}

Part cost increases with increasing fiber volume fraction, complexity, and mass, while production rate decreases with increasing complexity. Since tooling, capital, and direct labor costs for the spar cap range were unavailable, the development of a Cost Scaling Feature Factor will focus on how these scale with features such as part complexity, part mass, and fiber volume fraction. Indirect labor and utility costs are unchanged, varying only with production rate. Production rate will affect cost per part and scales with complexity, part mass, and fiber volume fraction.

As dedicated tooling, capital, and direct labor resource costs scale with features, so:

$$
\text { Resource Cost }=f[\text { Part Features } \times \text { Tooling, Capital, Direct Labor }]
$$

A Cost Scaling Feature Factor is defined as:

$$
\text { Cost Scaling Feature Factor, } F=1 /\left(1-V_{f}\right)^{x}(1-\bar{C})^{y}(1-\bar{M})^{z}
$$


where $V f=$ volume fraction of fiber, $\bar{C}=$ Complexity Factor, $\bar{M}=$ Mass Factor. $\mathrm{x}, \mathrm{y}$, and $\mathrm{z}$ are Cost Factor Indices. To simplify the analysis, $V f$ is assumed to be $56 \%$ for 35 to $75 \mathrm{~m}$, so will not vary. Complexity Factor $\bar{C}$ is the ratio of part complexity $n$ to maximum possible part complexity $N$ :

$$
\bar{C}=\text { Part Complexity /Maximum Part Complexity }=n / N
$$

The spar cap is a box spar with a constant cross-section with no holes or corners. Complexity is defined as the number of unidirectional (UD) fiber plies inserted into the spar cap mold tool prior to vacuum infusion. Minimum and maximum complexity is the minimum and maximum number of plies, respectively, required for the part to meet service specification. Maximum complexity is the number of plies above which manufacturing cost becomes too expensive. Due to confidentiality issues, spar cap manufacturers were unable to supply detailed information on the number and distribution of plies in the spar cap, so the minimum and maximum number of plies are unknown. For this analysis, an average complexity of 0.5 is chosen halfway between minimum complexity, which approaches zero, and maximum complexity, which approaches 1 . Therefore, the expression for Complexity Factor is:

$$
\bar{C}=\text { Number of UD Plies/Maximum number of UD Plies }
$$

In the Feature Factor expression, as complexity increases, $\bar{C}$ approaches $1,1-\bar{C}$ decreases, and the Cost Scaling Feature Factor increases.

Mass Factor $\bar{M}$ is defined as the ratio of spar cap mass $m$ to the maximum mass $M$ of the spar cap that can be cost-effectively produced:

$$
\bar{M}=\text { Mass of molded part/Maximum mass that can be molded }=m / M
$$

A value of $10,000 \mathrm{~kg}$ for a $100 \%$ carbon fiber $100 \mathrm{~m}$ spar cap was conservatively chosen as the upper mass limit for $M$ above which manufacturing is assumed to be prohibitively expensive using present resin infusion technology [29]. As $m$ approaches $M,(1-\bar{M})$ decreases and the Cost Scaling Feature Factor increases.

The production rate of a part decreases as part fiber volume fraction, complexity, and mass increase. Therefore, compared to the Reference Standard production rate, the maximum possible production rate is the production rate of the Reference Standard $\times$ Cost Scaling Feature Factor ${ }^{-1}$

$$
n_{r}=n_{r s}\left(1-V_{f}\right)^{x}(1-\bar{C})^{y}(1-\bar{M})^{z}
$$

where $n_{r s}$ is the annual production rate of the Reference Standard.

\subsubsection{Resource Costs: Material, Tooling, Capital, Direct Labor, Indirect Labor, Utilities}

\section{Material Cost}

For a carbon fiber composite, the fiber weight fraction is:

$$
\text { Fiber Weight Fraction }=\rho_{f} \operatorname{FVF}\left[\rho_{m}+\left(\rho_{f}-\rho_{m}\right] / \mathrm{FVP}\right.
$$

where $\rho_{f}$ carbon fiber density $=1550 \mathrm{~kg} / \mathrm{m}^{3} ; \rho_{m}$, epoxy matrix density $=1100 \mathrm{~kg} / \mathrm{m}^{3} ; \mathrm{FVF}=$ carbon fiber volume fraction $=0.56$

From Equation (9), the fiber weight fraction $=0.64$. Hence, the matrix weight fraction $=0.36$. Based on $500 \mathrm{~kg}$ for a $35 \mathrm{~m}$ blade spar cap (Figure 3):

$$
0.64 \times 500=321 \mathrm{~kg} \text { of carbon fiber, } 0.36 \times 500=179 \mathrm{~kg} \text { of resin }
$$

Fiber cost: $321 \mathrm{~kg} \times £ 33 / \mathrm{kg}=£ 10,593$. Resin cost $=179 \mathrm{~kg} \times £ 2 / \mathrm{kg}=£ 358$ so total cost $=£ 10,951$. 
The scrap rate for unidirectional fiberglass and carbon fiber material was 5\% [16]. The resin scrap rate was $15 \%$ [16], therefore, the material cost of a $35 \mathrm{~m}$ carbon fiber spar cap is $£ 11,979$ and the material cost of a $35 \mathrm{~m}$ E-glass fiber spar is $£ 3352$. Figure 4 in Section 4.1 shows material cost results for 35 to $75 \mathrm{~m}$.

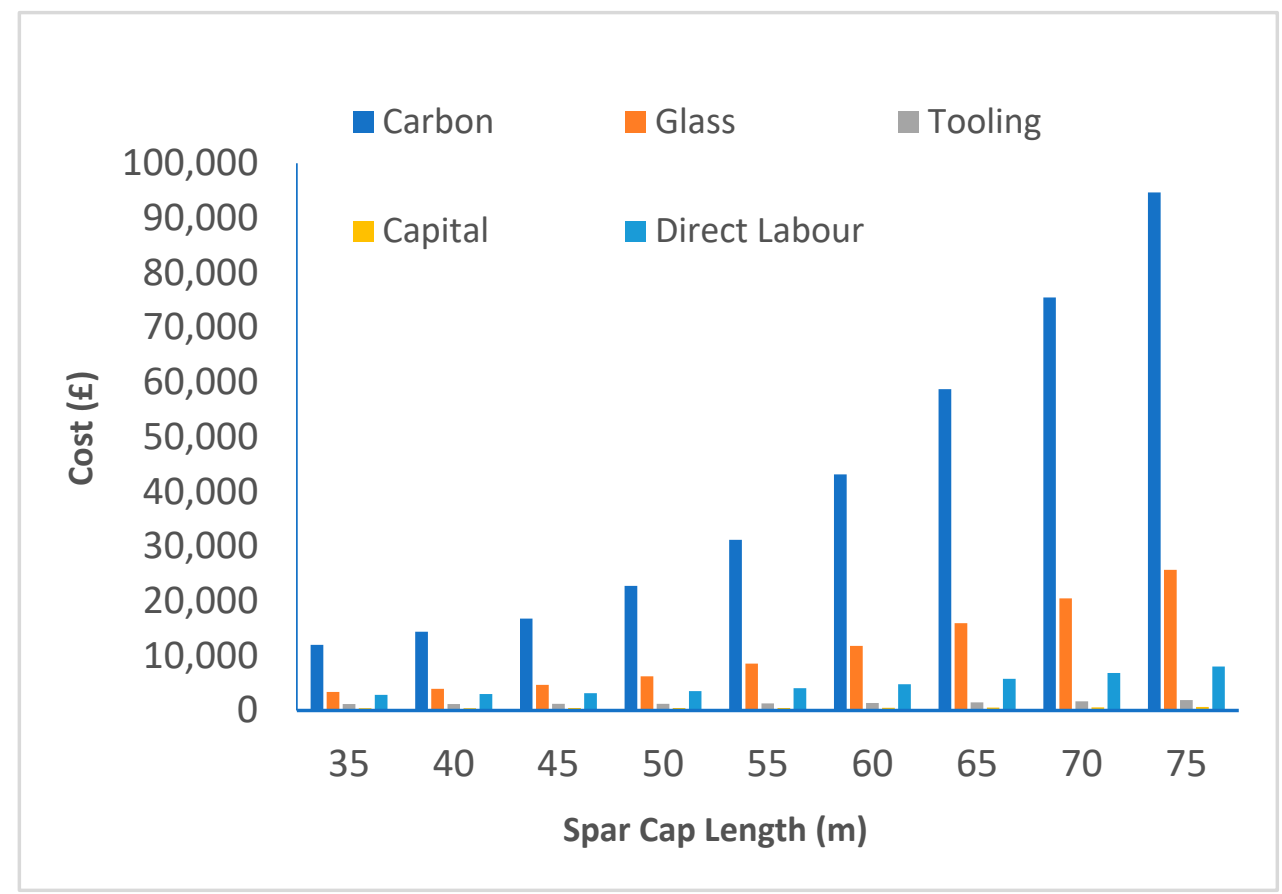

Figure 4. Resource cost variation with spar cap length.

Dedicated Tooling and Capital Cost

The dedicated tooling cost of a $35 \mathrm{~m}$ spar cap, defined as a Calibration Standard, will be more expensive than the tooling cost of a simple rectangular shape analogue of a $10 \mathrm{~m}$ long spar cap, defined as a Reference Standard, by the increased complexity of the Calibration Standard features compared with the complexity of the Reference Standard. These features are mass, complexity, and volume fraction. For the Reference Standard, volume fraction, complexity, and part mass are assumed to be much smaller than for the Calibration Standard. Therefore, dedicated tooling cost of the Calibration Standard is related to the tooling cost of the Reference Standard and Cost Scaling Feature Factor by:

Calibration Standard Dedicated Tooling Cost $=$ Reference Standard Tooling Cost $\times$ Feature Factor

$$
\text { Tooling Cost, 35mm Standard }=C_{t} \text { Reference Standard } /\left(1-V_{f}\right)^{x}(1-\bar{C})^{y}(1-\bar{M})^{z}
$$

where $C_{t}=$ Tooling Cost of Reference Standard

In general, spar cap dedicated tooling cost will vary with the Cost Scaling Feature Factor as:

$$
\text { Cost, 35mm Standard }=C_{t} \text { Reference Standard } /\left(1-V_{f}\right)^{x}(1-\bar{C})^{y}(1-\bar{M})^{z}
$$

Using the same reasoning as for tooling cost, the capital cost for making a $35 \mathrm{~m}$ Calibration Standard spar cap of given complexity, size, and fiber volume fraction compared with the capital cost of the Reference Standard will vary with the Cost Scaling Feature Factor as:

$$
\text { Capital Cost }=C_{c} \text { Reference Standard } /\left(1-V_{f}\right)^{x}(1-\bar{C})^{y}(1-\bar{M})^{z}
$$

where $C_{c}=$ Capital Cost of Reference Standard. 
Data for the Reference Standard (Table 2) and a $35 \mathrm{~m}$ spar cap Calibration Standard (Table 3) was used to infer Cost Factor Indices $x, y$ and $z$ for predicting GFRP and CFRP spar cap cost.

The following assumptions were made. Volume fraction $V f$ was taken as 0.56 , so $(1-V f)=0.44$. For 35 to $75 \mathrm{~m}$, volume fraction is assumed constant. Complexity Factor $\bar{C}=0.50$, so $(1-\bar{C})=0.50$, where complexity is assumed equal to 0.5 and maximum complexity equals 1 . Mass Factor $\bar{M}$ increases as $m$ increases in line with spar cap length.

For one $35 \mathrm{~m}$ blade spar cap, mass $m$ is $500 \mathrm{~kg}$ and Dedicated Tooling Cost is $£ 265,000$ for vacuum infusion (Table 3). The cost of the Reference Standard is $£ 20,000$ (Table 2). As dedicated tooling cost is a function of part volume fraction, part complexity, and part mass, $35 \mathrm{~m}$ Spar Cap tooling cost is related to the Reference Standard cost (Equation (11)) by:

$$
\begin{gathered}
£ 265,000=£ 20,000 \times \text { Cost Scaling Feature Factor } \\
£ 265,000=£ 20,000 /\left(1-V_{f}\right)^{x}(1-\bar{C})^{y}(1-\bar{M})^{z}
\end{gathered}
$$

where $\left(1-V_{f}\right)=0.44,(1-\bar{C})=0.50$, and $(1-\bar{C})$ varies with $m$ and $M$.

Tooling Cost, Capital Cost, Direct Labor Cost, and Production Rate are assumed the same regardless of composite. For part mass, CFRP was chosen instead of GFRP when deriving Factor Indices for cost elements, as CFRP spar caps over $50 \mathrm{~m}$ blade length increasingly become the norm. Should CFRP become competitive with GFRP, CFRP spar caps become more economic.

Figure 3 shows material mass for CFRP and GFRP as a quadratic function of spar cap length. The Cost Scaling Feature Factor scales with spar cap mass only while volume fraction and complexity have defined values of 0.44 and 0.50 , respectively. Therefore, values of Cost Factor Indices $x, y$ and $z$ will be greater than zero. In the absence of extensive tooling cost data for spar caps 40 to $75 \mathrm{~m}$, Cost Factor Indices $x, y$ and $z$ were estimated using a mathematical iterative method. One variable is fixed while the other variables are changed until a consistent set of numbers is derived that satisfies a relationship, in this case for tooling cost and capital cost.

Volume fraction plays a dominant role in composites manufacturing so index $x$ will be assumed greater than indices $y$ and $z$. For $M=10,000 \mathrm{~kg}$, Factor Index $x$ was initially given a constant value of 2 , while Factor Indices $y$ and $z$ were each assigned a value of 0.1 . By iteration, values of $y$ and $z$ were varied until Equation (11) was satisfied for $m=500 \mathrm{~kg}$. With three known values of $x, y$ and $z$ (Table 4), Dedicated Tooling Cost was estimated from Equations (11) and (14) for spar cap lengths 35 to $75 \mathrm{~m}$ for a maximum molding mass $M=10,000 \mathrm{~kg}$ (Figures 4 and 6).

$$
F=1 /\left(1-V_{f}\right)^{2}(1-\bar{C})^{1.39}(1-\bar{M})^{1}
$$

\begin{tabular}{|c|c|c|c|c|c|c|c|}
\hline \multirow{2}{*}{$\begin{array}{l}\text { Tooling } \\
\text { Cost }(£)\end{array}$} & \multicolumn{7}{|c|}{ Cost Factor Indices } \\
\hline & $x$ & $y$ & $z$ & Capital Cost $(£)$ & $x$ & $y$ & $z$ \\
\hline 103,499 & 2 & 0.1 & 0.1 & 839717 & 1.5 & 0.1 & 0.1 \\
\hline 139,399 & 2 & 0.5 & 0.5 & $1,130,982$ & 1.5 & 0.5 & 0.5 \\
\hline 229,967 & 2 & 1.2 & 0.8 & $1,865,776$ & 1.5 & 1.2 & 0.8 \\
\hline 256,476 & 2 & 1.35 & 0.9 & $1,914,776$ & 1.5 & 1.23 & 0.9 \\
\hline 265,000 & 2 & 1.39 & 1 & $1,935,000$ & 1.5 & 1.2452 & 1 \\
\hline
\end{tabular}

Table 4. Factor Indices for Tooling and Capital Cost resources.

Capital Cost requirements are infrastructure costs for a plant with one spar cap production line using a nominal cost of $£ 387 / \mathrm{sqm}$ for land and buildings [29,30]. Estimates for required floor space are summarized in Table $5[29,30]$. Total plant infrastructure capital expenditure (CAPEX) is depreciated over 20 years. CAPEX requirements are summarized below. 
Table 5. Floor space area.

\begin{tabular}{cc}
\hline Floor Space & Square Meters $\left.\mathbf{( m}^{\mathbf{2}}\right)$ \\
\hline Warehouse and Administration & 1000 \\
Spars & 4000 \\
Total & 5000 \\
\hline
\end{tabular}

The capital cost for one $35 \mathrm{~m}$ spar cap production line is $£ 387 \times 5000=£ 1,935,000$. The capital cost of the Reference Standard is $£ 227,500$ [29]. As with Tooling Cost, Capital Cost will be related to the Reference Standard cost (Equation (13)) by:

$$
£ 1,935,000=£ 227,500 /\left(1-V_{f}\right)^{x}(1-\bar{C})^{y}(1-\bar{M})^{z}
$$

As for Tooling Cost, the same mathematical iterative technique was used to derive Cost Factor Indices $x, y$ and $z$ that satisfied Equation (13) for $m=500 \mathrm{~kg}$ (35 m spar cap mass) with the value of $x$ for Volume Fraction assumed greater than $y$ and $z$. Index $x$ was initially assigned a constant value of 1.5 while Factor Indices $y$ and $z$ were each assigned a value of 0.1 . Values of $y$ and $z$ were varied until Equation (13) was satisfied for $m=500 \mathrm{~kg}$ (Table 4).

With three known values of $x, y$ and $z$, Capital Cost was estimated from Equations (13) and (15) for Spar Cap blade lengths ranging from 40 to $75 \mathrm{~m}$ for a maximum molding mass $M=10,000 \mathrm{~kg}$ (Figure 6).

$$
F=1 /\left(1-V_{f}\right)^{1.5}(1-\bar{C})^{1,2452}(1-\bar{M})^{1}
$$

Labor Cost

Labor cost is either a Direct Cost or Indirect Cost. Direct Labor costs are associated with the number and size of manufactured spar caps while Indirect Labor costs, such as Management and Administration, are assumed to be independent of spar cap size and number. The Direct Labor Cost for a $35 \mathrm{~m}$ blade spar cap was estimated as showen in Table 6.

Table 6. Direct Labor Cost for a single $35 \mathrm{~m}$ blade length spar cap [29,30].

\begin{tabular}{cccc}
\hline & Hours & Labor & Total Cost (Euros) \\
\hline Mold Preparation & 0.5 & 4 & 60 \\
Fabric Layup & 4 & 6 & 720 \\
Root studs & 5 & 2 & 300 \\
Vacuum bag & 0.5 & 4 & 60 \\
Infusion & 1.5 & 6 & 270 \\
Cure time & 5 & 1 & 150 \\
Consumable removal & 0.5 & 4 & 60 \\
Demold & 1 & 4 & 120 \\
Total & 18 & & 1740 \\
\hline
\end{tabular}

Example: Mold Preparation took $0.5 \mathrm{~h}$ with four operatives, as denoted by the number 4 . At a Direct Labor rate of 30 euros per hour, the total cost is $0.5 \times 4 \times 30=60$ euros. Similarly, Laminate Layup took fours hours with six operatives, so the cost is $4 \times 30 \times 6=720$ euros. At an exhange rate of $£ 0.91 / 1$ euro, the direct labor cost is $£ 1584$ for a $35 \mathrm{~m}$ spar cap.

Direct Labor cost is assumed to vary only with spar cap mass and was estimated for each spar cap, 35 to $75 \mathrm{~m}$, using the $35 \mathrm{~m} £ 1584$ Spar Cap Direct Labor cost as a baseline.

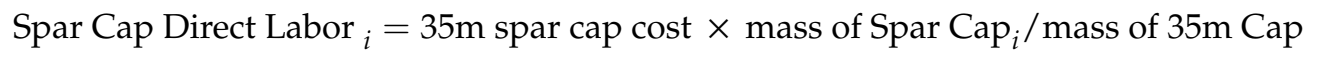

where spar cap Direct Labor Cost $t_{i}$ is the cost of a spar cap longer than $35 \mathrm{~m}$ (Figures 4 and 7). 


\section{Production Rate}

Production rate will decrease as fiber volume fraction, complexity, and mass increases. The Reference Standard has a production rate of 300 parts per year [29], which is the maximum possible production rate based on 18-h manufacturing time for one Standard, two 8-h shifts per day over seven days in a 48-week year. A period of $18 \mathrm{~h}$ per Standard is assumed to be the same for GFRP and CFRP. As for Tooling and Capital Cost, the same mathematical iterative technique was used to derive Cost Factor Indices $x, y$ and $z$ that satisfied Equation (8) for $m=500 \mathrm{~kg}$ (35 m spar cap mass) and $M=10,000$ $\mathrm{kg}$. Unlike Tooling and Capital, the value of $x$ for Volume Fraction was less than $y$ and $z$. Index $x$ was initially given a constant value of 0.01 , while Factor Indices $y$ and $z$ were assigned values of 0.006 and 0.2 , respectively. Compared to the Reference Standard production rate, the actual production rate is:

Actual Production Rate $=$ Production rate of Standard $\times$ Cost Scaling Feature Factor ${ }^{-1}$

$$
n_{r}=300\left(1-V_{f}\right)^{x}(1-\bar{C})^{y}(1-\bar{M})^{z}
$$

With three known values of $x, y$ and $z$, and a maximum production rate of 285 parts per year [29] for the $35 \mathrm{~m}$ spar cap Calibration Standard with $m=500 \mathrm{~kg}$, the production rate was estimated from Equation (17) for spar cap lengths 35 to $75 \mathrm{~m}$ for a maximum molding mass $\mathrm{M}=10,000 \mathrm{~kg}$ :

$$
285=300\left(1-V_{f}\right)^{0.01}(1-\bar{C})^{0.005}(1-\bar{M})^{0.1}
$$

\subsubsection{Cost Model Expression}

The Manufacturing Cost per Part expression (Equation (1)) is modified by inserting a Cost Scaling Feature Factor in the terms for Dedicated Tooling Cost, Capital Cost, and Production Rate.

$$
C_{m c}=\frac{m C_{m}}{(1-f)}+\frac{C_{t} F}{n_{r}}\left(1+\frac{n_{r}}{n_{t}}\right)+\frac{1}{n_{r}}\left[\left(\frac{C_{c} F}{L t_{\text {wo }}}\right)+n_{r} C_{\text {ohdirect }}+C_{\text {ohindirect }}+C_{\text {ohutilities }}\right]
$$

from which cost curves for CFRP and GFRP spar cap blades 35 to 75 m were derived. In Equation (19):

$C_{m c}=$ Manufacturing Cost;

$n_{r}=$ annual production rate (incorporating Cost Scaling Feature Factor);

$F=$ Feature Factor;

$n_{t}=$ Tool Life;

$\left(1+\frac{n_{r}}{n_{t}}\right)=$ Tool Life Factor;

$C_{\text {ohindirect }}=$ Indirect Labor;

$C_{\text {ohdirect }}=$ Direct Labor;

$C_{\text {ohutilities }}=$ Electricity costs.

\subsubsection{Levelized Cost of Electricity (LCOE)}

Data for wind turbine installed costs, lifetime electricity generation for 20 and 25 years, and lifetime $\mathrm{O}$ and $\mathrm{M}$ costs for 20 and 25 years were generated by the model using cost data from Table 7 . Retrofit spar cap cost data for CFRP and GFRP was taken from calculated cost curves for 35 to $75 \mathrm{~m}$. LCOE was then calculated and compared for each of the three scenarios. Costs were discounted in each year to arrive at a net present value for LCOE using a realistic discount rate. 
Table 7. Wind turbine capital costs, operational, and maintenance costs.

\begin{tabular}{cccc}
\hline $\begin{array}{c}\text { Spar Cap Length } \\
(\mathbf{m})\end{array}$ & $\begin{array}{c}\text { Rated Power } \\
(\mathbf{M W})\end{array}$ & $\begin{array}{c}\text { Wind Turbine } \\
\text { Installed Cost }(\boldsymbol{£} / \mathbf{k W})\end{array}$ & $\begin{array}{c}\text { O and M Cost } \\
(\boldsymbol{( \notin / k W / y e a r})\end{array}$ \\
\hline 35 & 1.59 & 1500 & \\
40 & 2.08 & 1450 & \\
45 & 2.63 & 1400 & \\
50 & 3.24 & 1350 & \\
55 & 3.93 & 1300 & \\
60 & 4.68 & 1250 & \\
65 & 5.49 & 1200 & \\
70 & 6.36 & 1150 & \\
75 & 7.32 & 1100 & \\
\hline
\end{tabular}

Assumptions

- Power generated from an off-shore wind speed of $15 \mathrm{~m} / \mathrm{s}$ (Equation (3)).

- Capacity Factor 0.2 for 20 years [1] and 0.3 for a 5 year extension following refit [1].

- $\quad$ Air density: $1.23 \mathrm{~g} / \mathrm{cm}^{3}$.

- Turbine installed costs, $\mathrm{O}$ and $\mathrm{M}$ costs [1].

- Discount rate: 7\% [35], power generation and $\mathrm{O}$ and $\mathrm{M}$ costs for 20 and 25 years.

- Cost data are based on three turbine blades.

Summary

A resource-based cost model was constructed from Equation (18) that accounts for materials, tooling, capital, labor, and utilities resources required for spar cap manufacture in the 35 to $75 \mathrm{~m}$ blade range. Available resource costs were material mass data for the 35 to $75 \mathrm{~m}$ range, tooling, capital, labor, and utilities for a $35 \mathrm{~m}$ spar cap (Calibration Standard) and a $10 \mathrm{~m}$ spar cap analogue (Reference Standard), and production rate for the $35 \mathrm{~m}$ spar cap. Technical cost modelling (TCM), was used to derive a Cost Scaling Feature Factor and Cost Factor Indices from known cost data in order to predict production rate and tooling, capital, and direct labor costs for the 40 to $75 \mathrm{~m}$ spar cap range.

To estimate Levelized Cost of Energy for the three scenarios, cost data for turbine investment costs and operational and maintenance costs were calculated by the model based on literature values for investment cost per $\mathrm{kW}, \mathrm{O}$ and $\mathrm{M}$ cost $/ \mathrm{kW} / \mathrm{year}$, and rated power for each blade length, 35 to $75 \mathrm{~m}$.

\section{Results and Discussion}

Based on assumptions and key parameters (see below), cost curves were derived from predicted costs for 35 to $75 \mathrm{~m}$, from which GFRP retrofit costs and $3 \mathrm{~m}$ longer length CFRP retrofit costs were taken. Using model-calculated data for turbine investment costs, $\mathrm{O}$ and $\mathrm{M}$ costs, and GFRP and CFRP retrofit costs, LCOE for the three scenarios was calculated and compared.

Assumptions, Key Parameters and Definitions

- $\quad$ Tool Life $n_{t}: 1250$ parts [43].

- Capital cost amortised over 20 years, buildings and equipment $85 \%$ utilised.

- E-glass and carbon fiber composites spar caps: 35 to $75 \mathrm{~m}$ blade length.

- Assume $M=10,000 \mathrm{~kg}$ for upper molding mass limit. Glass = GFRP, Carbon = CFRP.

- Production Rate $n_{r} 285$ ppa for $35 \mathrm{~m}$ spar cap; 272 ppa for $75 \mathrm{~m}$ spar cap. PPA = parts per annum.

- Prices, 2018: Carbon fiber: $£ 5 / \mathrm{kg}, £ 33 / \mathrm{kg}$. Glass fiber: $£ 2 / \mathrm{kg}$. Resin: $£ 3 / \mathrm{kg}$.

- Capacity Factor: 0.2 for 20 years [1], 0.3 for 5 year extension [1]. 


\subsection{Resource Costs: Material, Tooling, Capital, Labor}

At annual production rates of 285 for $35 \mathrm{~m}$ and 272 for $75 \mathrm{~m}$, material is the highest contributor to total cost. All resource costs increase as a quadratic function of spar cap mass with blade length as a proxy for mass (Figures 4 and 6). In Figure 4, material (GFRP and CFRP) and direct labor costs increase as a proportion of total cost from 35 to $75 \mathrm{~m}$, while indirect labor, capital, tooling, and utilities decrease. CFRP rises from $65 \%$ to $83 \%$ compared with GFRP, which rises from $39 \%$ to $64 \%$, dominating total cost to a much greater extent as carbon is 10 times more expensive than glass.

\subsection{Manufacturing Cost Data}

Manufacturing cost data was supplied as upper and lower limits for both CFRP and GFRP (Table 8, Figure 5a,b). Model data for CFRP and GFRP plotted on the same graphs showed the same quadratic relationship. Correlation coefficients are 0.99 and 1 for the model and manufacturing data, so the assumptions of equal Cost Factor Indices for both CFRP and GFRP, and constant complexity with spar cap length appear valid. Mid-point manufacturing data was compared with the model to derive cost curves for GFRP and CFRP (Table 9, Figure 5c,d). Figure 5a,c show good agreement between model-derived CFRP cost data and the manufacturer's data, with an average difference of $6.8 \%$ between the model and mid-point data. GFRP shows a significant $20.6 \%$ deviation between the model and mid-point data (Figure $5 b, d$ ), as the model increasingly underestimates the cost for GFRP spar caps above $55 \mathrm{~m}$ compared with the manufacturer's estimate.

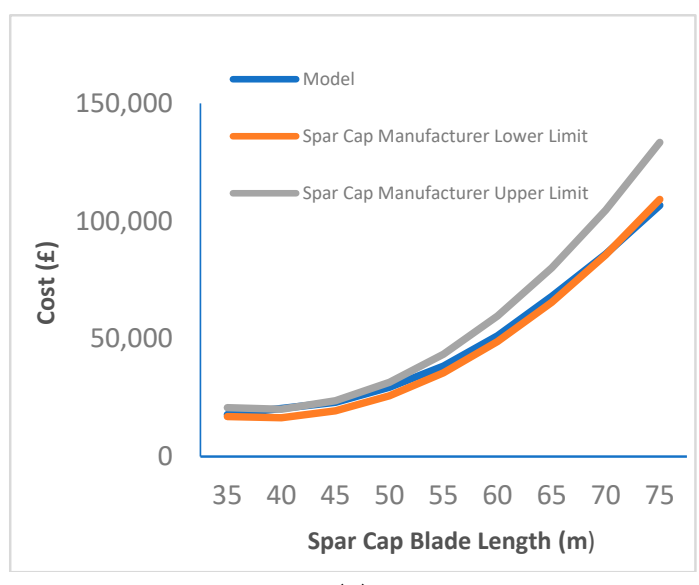

(a)

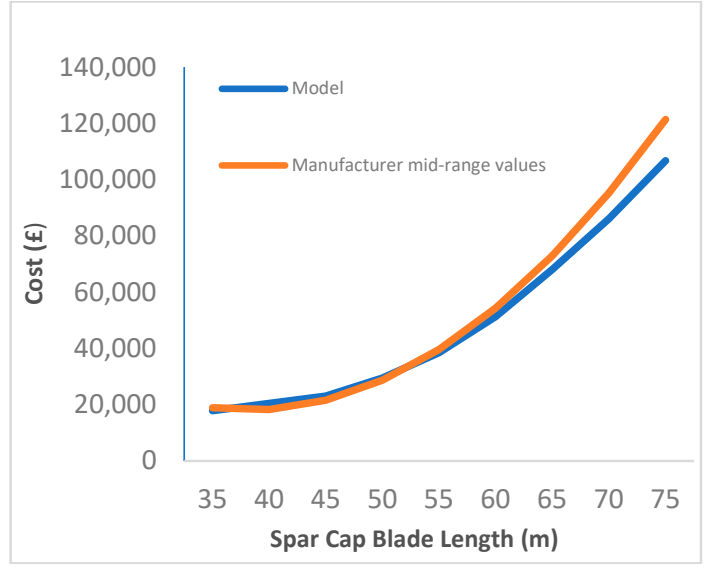

(c)

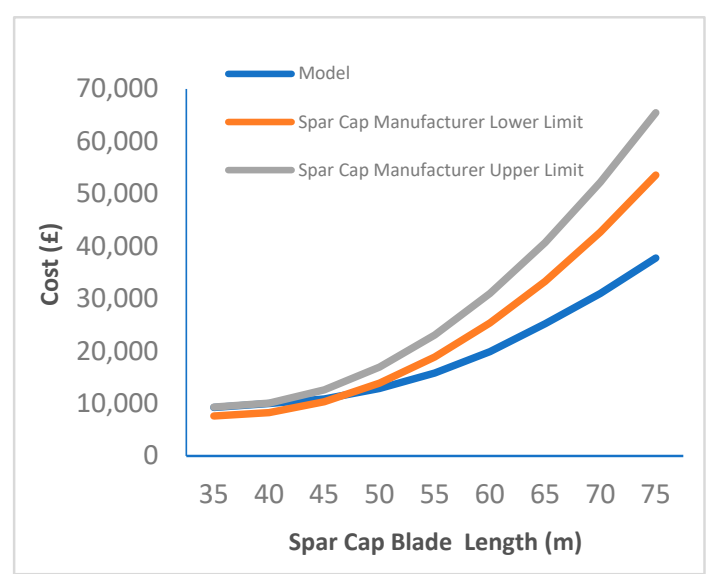

(b)

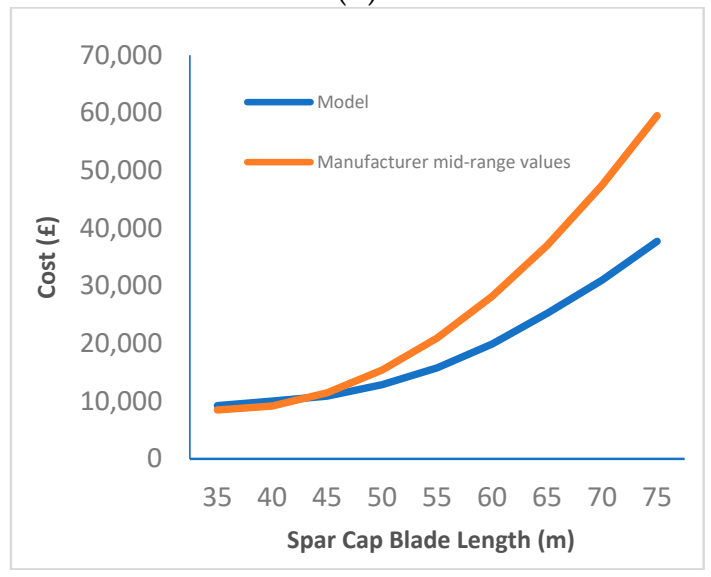

(d)

Figure 5. Comparison of model-generated manufacturing cost data with cost data from a spar cap manufacturer. (a) carbon reinforced polymer composite (CFRP) model and manufacturer data. (b) glass fiber reinforced polymer composite (GFRP) model and manufacturer data. (c) CFRP model and mid-range manufacturer data. (d) GFRP model and mid-range manufacturer data. 
Table 8. CFRP, GFRP: model data compared with manufacturer data [29].

\begin{tabular}{ccccccc}
\hline \multicolumn{3}{c}{ Manufacturer CFRP } & \multicolumn{2}{c}{ Manufacturer GFRP } \\
\hline $\begin{array}{c}\text { Blade } \\
\text { Length }(\mathbf{m})\end{array}$ & $\begin{array}{c}\text { Model } \\
\text { CFRP }(\boldsymbol{E})\end{array}$ & Lower Limit & Upper Limit & $\begin{array}{c}\text { Model } \\
\text { GFRP }(\boldsymbol{E})\end{array}$ & Lower Limit & Upper Limit \\
\hline 35 & 17,866 & 16,968 & 20,738 & 9240 & 7620 & 9314 \\
40 & 20,430 & 16,464 & 20,122 & 9992 & 8233 & 10,063 \\
45 & 22,995 & 19,395 & 23,705 & 10,874 & 10,316 & 12,608 \\
50 & 29,408 & 25,761 & 31,485 & 12,855 & 13,863 & 16,943 \\
55 & 38,391 & 35,579 & 43,485 & 15,789 & 18,874 & 23,068 \\
60 & 51,236 & 48,832 & 59,684 & 19,899 & 25,352 & 30,986 \\
65 & 67,960 & 65,520 & 80,080 & 25,202 & 33,298 & 40,698 \\
70 & 86,009 & 85,641 & 104,673 & 31,001 & 42,709 & 52,201 \\
75 & 106,706 & 109,201 & 133,467 & 37,743 & 53,589 & 65,497 \\
\hline
\end{tabular}

Table 9. Model part cost data vs. spar cap manufacturer mid-point data [29].

\begin{tabular}{ccccccc}
\hline $\begin{array}{c}\text { Blade } \\
\text { Length }(\mathbf{m})\end{array}$ & $\begin{array}{c}\text { Model } \\
\text { CFRP }(\boldsymbol{(})\end{array}$ & $\begin{array}{c}\text { Manufacturer } \\
\text { CFRP Cost }(\boldsymbol{(})\end{array}$ & $\begin{array}{c}\text { Variance } \\
\mathbf{( \% )}\end{array}$ & $\begin{array}{c}\text { Model } \\
\text { GFRP }(\boldsymbol{(})\end{array}$ & $\begin{array}{c}\text { Manufacturer } \\
\text { GFRP Cost }(\boldsymbol{(})\end{array}$ & $\begin{array}{c}\text { Variance } \\
\mathbf{( \% )}\end{array}$ \\
\hline 35 & 17,866 & 18,853 & 5.23 & 9240 & 8467 & 8.36 \\
40 & 20,430 & 18,293 & 10.46 & 9992 & 9148 & 8.44 \\
45 & 22,995 & 21,550 & 6.28 & 10,874 & 11,462 & 5.41 \\
50 & 29,408 & 28,623 & 2.67 & 12,855 & 15,403 & 16.54 \\
55 & 38,391 & 39,532 & 2.89 & 15,789 & 20,971 & 24.71 \\
60 & 51,236 & 54,258 & 5.57 & 19,899 & 28,169 & 29.36 \\
65 & 67,960 & 72,800 & 6.65 & 25,202 & 36,998 & 31.88 \\
70 & 86,009 & 95,157 & 9.61 & 31,001 & 47,455 & 34.67 \\
75 & 106,706 & 121,334 & 12.06 & 37,743 & 59,543 & 36.61 \\
\end{tabular}

Direct Labor cost may be higher for heavier GFRP caps than for lighter CFRP caps which would account for the increasing divergence between the model and manufacturer supplied data. Figure 6 shows that the increase in Direct Labor cost has a much bigger impact on overall cost than other non-material costs. Therefore, the assumption that Direct Labor costs are equal for GFRP and CFRP may be incorrect.

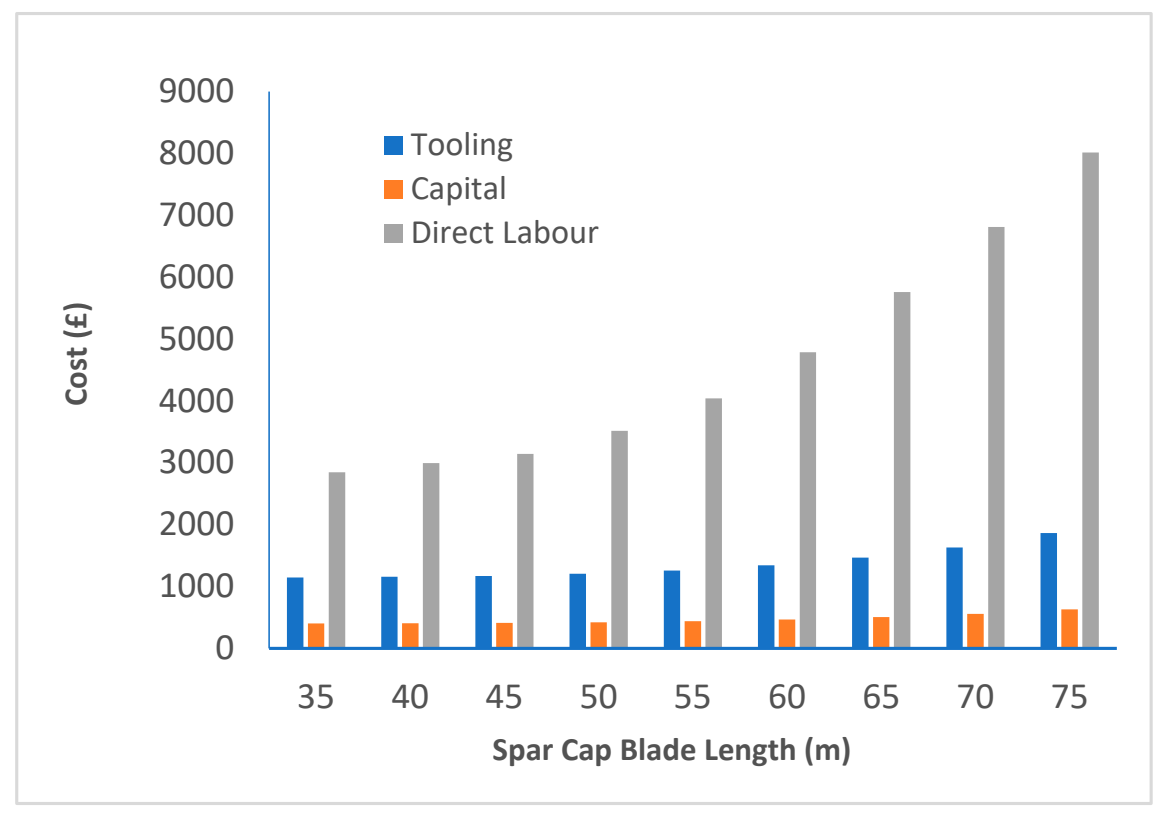

Figure 6. Variation of tooling, capital, and direct labor with spar cap length. 


\subsection{Manufacturing Complexity and Organizational Learning}

Organizational learning is defined as a conscious attempt by organizations to improve productivity, effectiveness, and innovation in complex economic and technological market conditions. The greater the uncertainties, the greater the need for learning. Learning enables quicker and more effective responses to a complex and dynamic environment [18]. Manufacturing Complexity is broadly defined as the number of items and steps in a manufacturing process and the degree of relationship between them [18]. One major item is direct labor. It is proposed that with higher manufacturing complexity, organizational learning is lower, resulting in higher cost. Manufacturing Complexity and Organizational Learning can be related by:

$$
\text { Manufacturing Complexity, } \alpha=k(1 / \beta)^{y}
$$

where $\beta=$ Organizational Learning, $k=$ constant of proportionality, $y=$ power index.

Organizational Learning can be defined as the ratio of Direct Labor Cost for CFRP to Direct Labor Cost for GFRP, and will equal 1 when Direct Labor Costs for GFRP and CFRP are equal:

$$
\text { Organisational Learning, } \beta=\frac{\text { Direct Labor Cost, CFRP Spar Cap }}{\text { Direct Labor Cost, GFRP Spar Cap }}
$$

Assuming a worst case where GFRP spar cap direct labor cost is 10 times that of a CFRP spar cap, $\beta=0.1$ and manufacturing complexity $\alpha=10$ if $y$ and $k=1$ (Equation (20)). As learning increases and if $\beta$ increases in 0.1 increments in response until $\alpha=1$ when $\beta=1$, the following curve is derived (Figure 7):

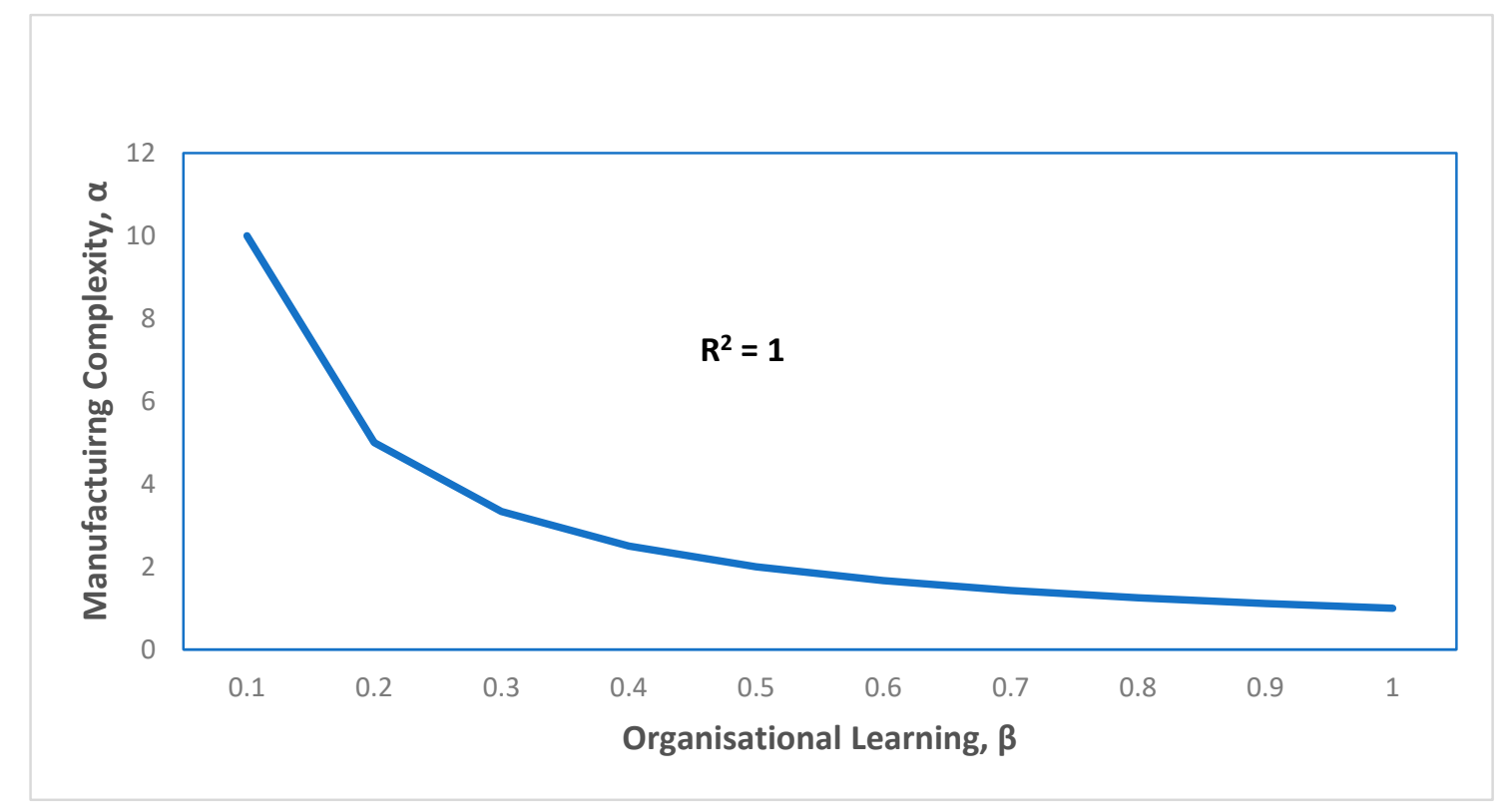

Figure 7. Manufacturing Complexity vs Organizational Learning.

Figure 7 is a theoretical plot of manufacturing complexity vs. organizational learning from which a manufacturing complexity factor was derived that accounted for the wide divergence in cost between manufacturer and model for GRFP spar caps due to increased Direct Labor Cost for GFRP. A corrected GFRP cost curve (Figure 8) incorporates this factor for increased Direct Labor Cost. If Organizational Learning $\beta$ is less than 1 because Direct Labor Cost for GFRP is higher than for CFRP, increasing the Direct Labor Cost for GFRP by a Manufacturing Complexity factor of 4 from the curve results in better 
agreement between model and manufacturer, with a reduced average deviation of $8.3 \%$ (Figure 9). Equation (18) can be modified to:

$$
C_{m c}=\frac{m C_{m}}{(1-f)}+\frac{C_{t} F}{n_{r}}\left(1+\frac{n_{r}}{n_{t}}\right)+\frac{1}{n_{r}}\left[\left(\frac{C_{c} F}{L t_{w o}}\right)+\alpha n_{r} C_{\text {ohdirect }}+C_{\text {ohindirect }}+C_{\text {ohutilities }}\right]
$$

where $\alpha$ is Manufacturing Complexity.

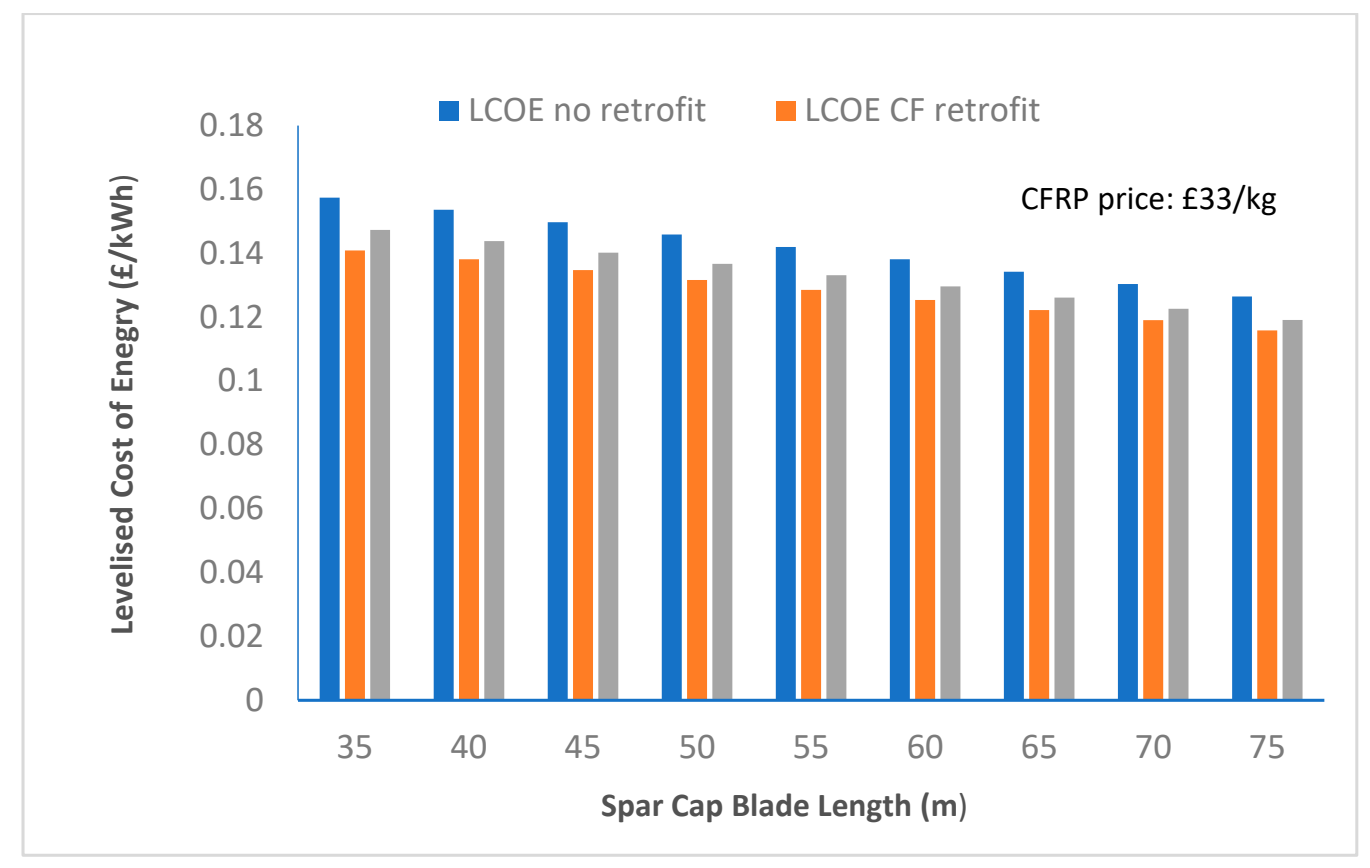

Figure 8. LCOE vs. spar cap length, 35-75 m, CFRP and GFRP.

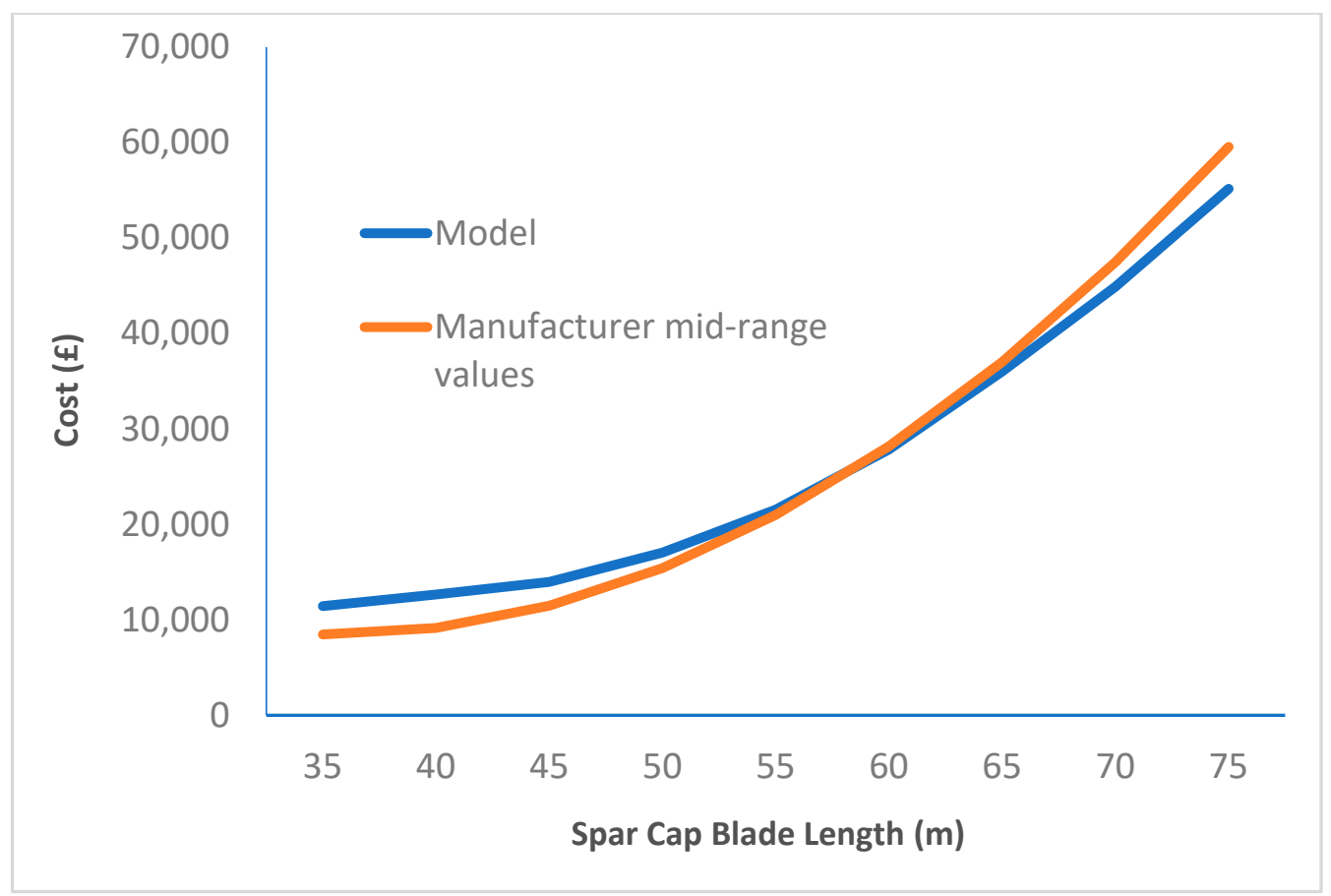

Figure 9. GFRP spar cap cost curve: model vs. manufacturer (mid-range cost data). 


\subsection{Commercial Feasibility, Material Efficiency. Levelized Cost of Electricity}

The global weighted average Levelized Cost of Electricity (LCOE) for offshore wind is predicted to fall to $£ 0.045 / \mathrm{kWh}$ from $£ 0.078 / \mathrm{kWh}$ (2014) by 2020 , with UK offshore wind electricity priced at $£ 0.057 / \mathrm{kWh}$ in 2019 [1]. In a context of decreasing prices, retrofitting blades for wind turbine life extension is emerging as an alternative strategy to very expensive system redesign and replacement options. The environmental effects of material production and processing are becoming critical [40].

GFRP spar caps over $50 \mathrm{~m}$ blade length show increased blade flexure and excessive weight on turbine hub and bearings [31,48-50]. Specific stiffness for CFRP is higher than for GFRP, therefore CFRP blades will flex less. For the same weight, CFRP blades are longer than GFRP blades and will generate more power. Levelized Cost of Electricity was modelled for three scenarios: a 20-year baseline rated turbine life with GFRP blade lengths 35 to $75 \mathrm{~m}$ (Table 10); a 5-year life extension with a GFRP retrofit for each blade at the same length (Table 10); and $3 \mathrm{~m}$ longer CFRP retrofits for each blade length 35 to $75 \mathrm{~m}$ (Table 11). For both retrofit scenarios, CFRP price was varied to assess CFRP retrofit feasibility.

Table 10. Levelized Cost of Electricity (LCOE): GFRP refit with same length GFRP blade.

\begin{tabular}{cccc}
\hline $\begin{array}{c}\text { Spar Cap } \\
\text { Length }(\mathbf{m})\end{array}$ & $\begin{array}{c}\text { GFRP, 20 Years } \\
\text { LCOE }(\boldsymbol{£} / \mathbf{k W h})\end{array}$ & $\begin{array}{c}\text { GFRP Retrofit, 25 Years } \\
\text { LCOE }(\boldsymbol{£} / \mathbf{k W h})\end{array}$ & $\begin{array}{c}\text { Reduction in } \\
\text { LCOE }(\%)\end{array}$ \\
\hline 35 & 0.157 & 0.147 & 6.42 \\
40 & 0.154 & 0.144 & 6.40 \\
45 & 0.150 & 0.140 & 6.37 \\
50 & 0.146 & 0.137 & 6.31 \\
55 & 0.142 & 0.133 & 6.23 \\
60 & 0.138 & 0.130 & 6.13 \\
65 & 0.134 & 0.126 & 6.03 \\
70 & 0.130 & 0.123 & 5.92 \\
75 & 0.126 & 0.119 & 5.80 \\
\hline
\end{tabular}

Table 11. LCOE: GFRP and longer length CFRP refit, 5 -year extension. CFRP price: $£ 33 / \mathrm{kg}$.

\begin{tabular}{ccccc}
\hline $\begin{array}{c}\text { Spar Cap } \\
\text { Length }(\mathbf{m})\end{array}$ & $\begin{array}{c}\text { GFRP, 20 Years } \\
\text { LCOE }(\boldsymbol{(} / \mathbf{k W h})\end{array}$ & $\begin{array}{c}\text { Spar Cap } \\
\text { Length }(\mathbf{m})\end{array}$ & $\begin{array}{c}\text { CFRP Retrofit 25 Years } \\
\text { LCOE }(\boldsymbol{E} / \mathbf{k W h})\end{array}$ & $\begin{array}{c}\text { Reduction in } \\
\text { LCOE }(\mathbf{\%})\end{array}$ \\
\hline 35 & 0.157 & 38 & 0.141 & 10.49 \\
40 & 0.154 & 43 & 0.138 & 10.10 \\
45 & 0.150 & 48 & 0.135 & 10.02 \\
50 & 0.146 & 53 & 0.132 & 9.77 \\
55 & 0.142 & 58 & 0.129 & 9.49 \\
60 & 0.138 & 63 & 0.125 & 9.21 \\
65 & 0.134 & 68 & 0.122 & 8.94 \\
70 & 0.130 & 73 & 0.119 & 8.66 \\
75 & 0.126 & 78 & 0.116 & 8.39 \\
\hline
\end{tabular}

Tables 10 and 11, and Figure 8, compare LCOE for glass blades from 35 to 75 for a 20-year life with LCOE for same length GFRP blade retrofits for life extension to 25 years, and LCOE for $3 \mathrm{~m}$ longer length CFRP blade retrofits for life extension to 25 years. The CFRP price was $£ 33 / \mathrm{kg}$. LCOE decreases for GFRP retrofits as more power is generated compared to the 20-year baseline. A $35 \mathrm{~m}$ GFRP retrofit decreases LCOE by $6.4 \%$, with the percentage decrease declining to $5.8 \%$ at $75 \mathrm{~m}$ (Table 10). A longer length CFRP retrofit for a $35 \mathrm{~m}$ blade (Table 11) decreases LCOE by $10.49 \%$ as the longer CFRP refit generates more power. The percentage decrease in LCOE declines to $8.39 \%$ at $75 \mathrm{~m}$. In both cases, the decline is due to dominance of material and labor costs at annual production rates of 285 for $35 \mathrm{~m}$ and 272 for $75 \mathrm{~m}$, with material and direct labor increasing as a proportion of overall cost and increasing absolute blade cost with length.

Figure 10 compares LCOE for the three scenarios at a CFRP price of $£ 5 / \mathrm{kg}$. Tables 12 and 13 show how the decrease in LCOE percentage reduction for longer length CFRP retrofits compared with GFRP 
retrofits varies with CFRP price. At $£ 33 / \mathrm{kg}$, the LCOE percentage reduction for CFRP is lower for all blade lengths and more marked with increase in blade length than for $£ 5 / \mathrm{kg}$ (Figures 9 and 10). As the percentage reduction in LCOE for CFRP retrofits decreases with increasing blade length, this implies that at some blade length greater than $75 \mathrm{~m}$, a CFRP retrofit will give the same reduction in LCOE compared with a GFRP retrofit. Above this length, a CFRP retrofit will not be economically viable due to much higher material price compared with GFRP. Figure 11 shows that a lower CFRP price will increase the viability of CFRP retrofits at higher blade lengths (Tables 12 and 13).

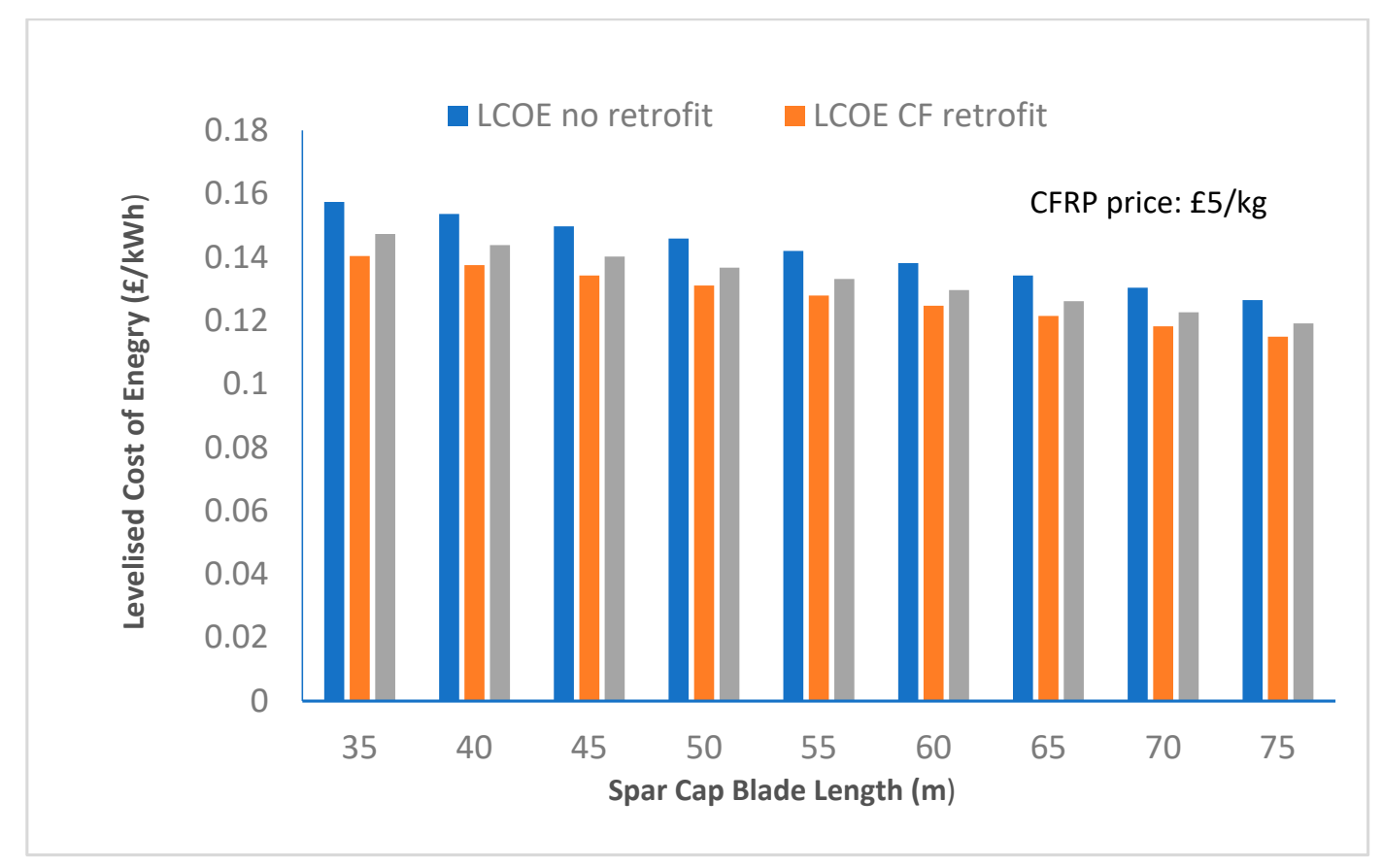

Figure 10. LCOE vs. spar cap length, 35-75 m, CFRP and GFRP.

Table 12. LCOE: GFRP refit compared with LCOE for CFRP refit. CFRP price: $£ 33 / \mathrm{kg}$.

\begin{tabular}{ccccc}
\hline $\begin{array}{c}\text { Spar Cap } \\
\text { Length }(\mathbf{m})\end{array}$ & $\begin{array}{c}\text { GFRP, Retrofit 25 Years } \\
\text { LCOE }(\boldsymbol{f} / \mathbf{k W h})\end{array}$ & $\begin{array}{c}\text { Spar Cap } \\
\text { Length }(\mathbf{m})\end{array}$ & $\begin{array}{c}\text { CFRP Retrofit 25 Years } \\
\text { LCOE }(\boldsymbol{f} / \mathbf{k W h})\end{array}$ & $\begin{array}{c}\text { Reduction in LCOE } \\
\text { for CFRP }(\mathbf{\%})\end{array}$ \\
\hline 35 & 0.147 & 38 & 0.141 & 4.36 \\
40 & 0.144 & 43 & 0.138 & 3.95 \\
45 & 0.140 & 48 & 0.135 & 3.91 \\
50 & 0.137 & 53 & 0.132 & 3.70 \\
55 & 0.133 & 58 & 0.129 & 3.48 \\
60 & 63 & 0.125 & 3.28 \\
65 & 0.130 & 68 & 0.122 & 3.10 \\
70 & 0.126 & 73 & 0.119 & 2.91 \\
75 & 0.123 & 78 & 0.116 & 2.75 \\
\hline
\end{tabular}

Table 13. LCOE: GFRP refit compared with LCOE for CFRP refit. CFRP price: $£ 5 / \mathrm{kg}$.

\begin{tabular}{ccccc}
\hline $\begin{array}{c}\text { Spar Cap } \\
\text { Length }(\mathbf{m})\end{array}$ & $\begin{array}{c}\text { GFRP, Retrofit } \\
\text { 25 Years LCOE }(\boldsymbol{E} / \mathbf{k W h})\end{array}$ & $\begin{array}{c}\text { Spar Cap } \\
\text { Length }(\mathbf{m})\end{array}$ & $\begin{array}{c}\text { CFRP Retrofit } \\
\text { 25 Years LCOE }(\boldsymbol{E} / \mathbf{k W h})\end{array}$ & $\begin{array}{c}\text { Reduction in LCOE, } \\
\text { CFRP }(\mathbf{\%})\end{array}$ \\
\hline 35 & 0.147 & 38 & 0.140 & 4.72 \\
40 & 0.144 & 43 & 0.137 & 4.39 \\
45 & 0.140 & 48 & 0.134 & 4.26 \\
50 & 0.137 & 53 & 0.131 & 4.09 \\
55 & 0.133 & 58 & 0.128 & 3.95 \\
60 & 0.130 & 63 & 0.124 & 3.82 \\
65 & 0.126 & 73 & 0.121 & 3.72 \\
70 & 0.123 & 78 & 0.118 & 3.62 \\
75 & 0.119 & & 0.115 & 3.53 \\
\hline
\end{tabular}




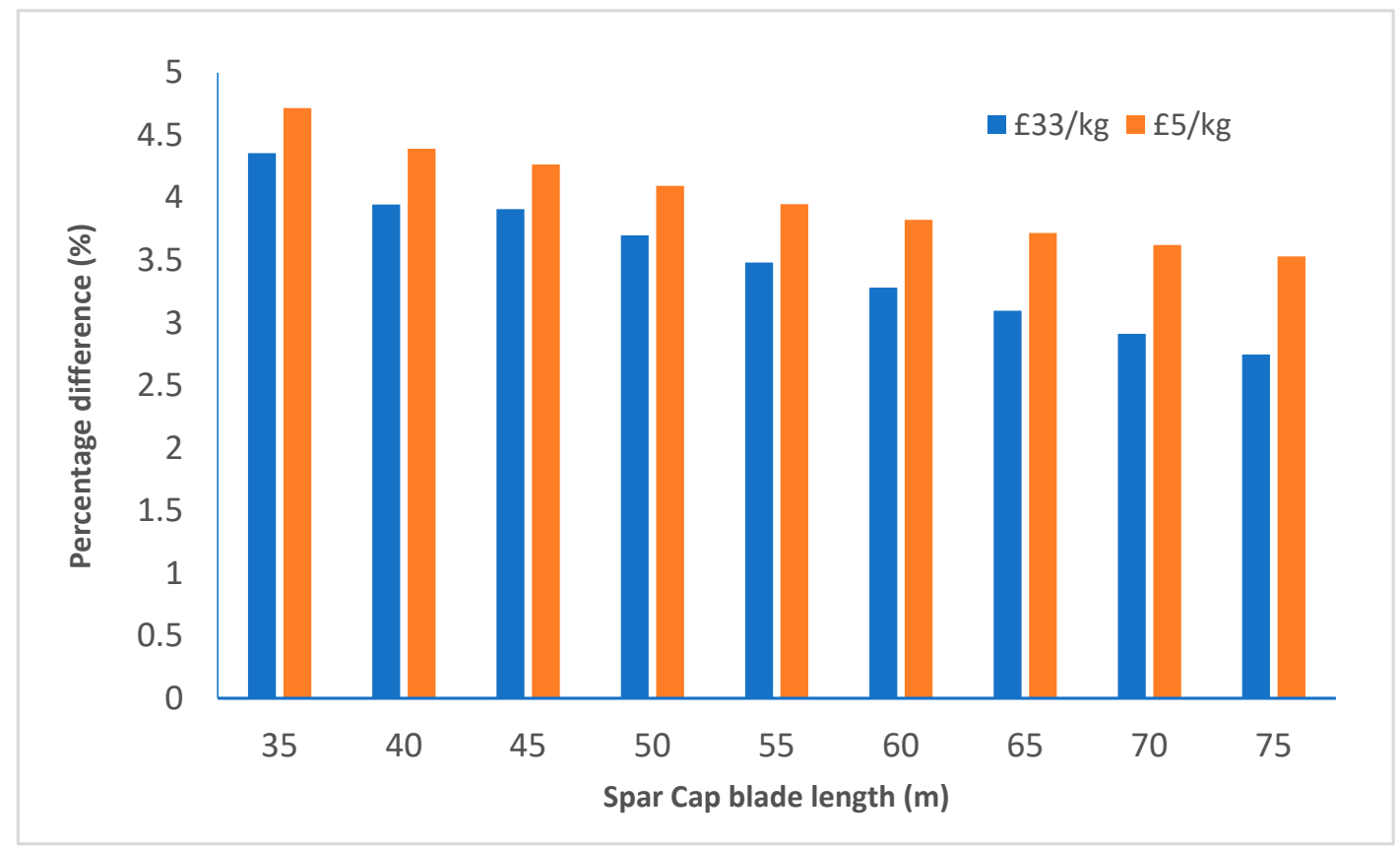

Figure 11. Decrease in percentage reduction for LCOE at two CFRP prices.

This is a simplified sensitivity analysis, as the only variable changed was CFRP price. If only material was considered, CFRP retrofits would not be financially viable compared with GFRP retrofits above a certain blade length. However, new CFRP retrofits will generate more power with reduced LCOE, since longer and thinner CFRP blades retrofits are aerodynamically more efficient than thicker GFRP retrofits. Taken together, these factors may outweigh the cost of very expensive CFRP retrofits, as more power will be generated than when length alone is considered.

Other factors will affect the viability of longer length CFRP blade retrofits. Adjacent turbines with longer blade lengths will induce increased turbulence with a reduction in power output. Planning restrictions may limit retrofit length. Lighter weight CFRP retrofits may require a braking system on the nacelle to prevent rotation at greater than rated wind speed. The environmental impact cost of increased material consumption in a turbine system redesign and complete replacement scenario should be accounted for compared with the costs of life extension by blade retrofit. In any feasibility assessment of blade retrofits compared with a 20-year baseline turbine life, a wide variety of conflicting cost, design, planning, installation, and operational performance constraints must be accounted for if an optimum retrofit solution is to be obtained.

\section{Summary}

The market for wind energy is increasingly competitive as electricity prices fall. Existing cost models focus on entire wind turbine systems. However, system-level design and complete turbine replacement are very expensive strategies for lowering Levelized Cost of Energy (LCOE). Another issue is the environmental cost of increased material consumption. Consequently, turbine manufacturers are starting to focus on the feasibility of retrofitting existing turbine designs with longer CFRP spar cap blades to extend wind turbine life.

A cost model was developed to assess the commercial feasibility of retrofitting same length turbine glass and longer length carbon fiber blades in the 35 to $75 \mathrm{~m}$ range. Tooling and capital cost data were unavailable for blades lengths 40 to $75 \mathrm{~m}$. A wind turbine blade manufacturer supplied cost data for a $10 \mathrm{~m}$ spar cap analogue part, termed a Reference Standard, made from either glass or carbon fiber composite, and a $35 \mathrm{~m}$ blade box spar cap, termed a Calibration Standard. Glass and carbon fiber composite mass data for a box spar cap design was obtained from a cost and engineering study of spar caps in the 35 to $75 \mathrm{~m}$ spar cap range. A technical cost modelling (TCM) approach was employed, in 
which cost scales with features defined as mass, volume fraction, and complexity to derive tooling and capital cost data for spar cap lengths 40 to $75 \mathrm{~m}$. In TCM, cost resources can be approximate and isolated, giving the model flexibility, scalability, and adaptability. As more data becomes available, detail can be added to improve predictive power.

Data was generated by the model to derive cost curves for GFRP and CFRP composite spar caps from 35 to $75 \mathrm{~m}$ blade length with annual production rates of 285 and 272 parts, respectively. Cost Scaling Feature Factors incorporating Cost Factor Indices derived from material, reference, and calibration cost data were developed to predict how spar cap costs such as dedicated tooling scale with part features. The only feature varied was part mass, with volume fraction and part complexity remaining constant. For both CFRP and GFRP, material and direct labor costs increase as a proportion of total cost from 35 to $75 \mathrm{~m}$, while indirect labor, capital, tooling, and utilities decrease. GFRP and CFRP cost curves were compared with independent cost data from a manufacturer for a box spar turbine blade design in 35 to $75 \mathrm{~m}$ blade lengths.

For CFRP, the average variation was $6.8 \%$ between the model and manufacturer's cost, while for GFRP the variation was $20.5 \%$. An expression was introduced relating organizational learning to manufacturing complexity. If direct labor cost is assumed greater for heavier GFRP compared with CFRP by a manufacturing complexity factor of 4 , the variation is $8.6 \%$. For a part in which detailed cost data is not known, a rough order of magnitute (ROM) estimation of costs that is within $20 \%$ of the expected cost is deemed acceptable. Therefore, based on the cost data provided and asuumptions adopted, the model is considered validated.

The cost of same length retrofit GFRP spar cap blades and $3 \mathrm{~m}$ longer CFRP blades was taken from the cost curve. Using precalculated turbine investment, operational and maintenance costs, and power generation data for a 20-year lifetime, LCOE was calculated for 20-year baseline GFRP blade turbines ranging from 35 to $75 \mathrm{~m}$. LCOE for GFRP and CFRP turbine retrofits was then calculated and compared by inserting model-derived retrofit costs. Sensitivity analysis for one variable, CFRP material cost, was performed for blade retrofit feasibility. LCOE reduction for longer length CFRP retrofits compared with same length GFRP retrofits decreased as blade length increased, implying that at some blade length above $75 \mathrm{~m}$, CFRP retrofits may not be viable. Lower CFRP prices will increase CFRP retrofit viability at longer blade lengths.

\section{Conclusions and Recommendations for Further Work}

The model is intended as a tool for assessing the economic feasibility, in terms of reduced LCOE, of retrofitting wind turbines with new spar cap blades. Estimated spar cap costs were within $6.8 \%$ and $8.3 \%$ (CFRP and GFRP, respectively) of a manufactuer's cost estimates of spar cap blade lengths from 35 to $75 \mathrm{~m}$ having the same box spar design. LCOE was calculated for 20-year baseline GFRP blade turbines ranging from 35 to $75 \mathrm{~m}$. The reduction in LCOE for longer length CFRP retrofits compared with same length GFRP retrofits decreased as blade length increased, implying that CFRP retrofits may not be viable at some blade length above $75 \mathrm{~m}$. A lower CFRP price will increase CFRP retrofit viability at longer blade lengths.

The model has two disadvantages. Firstly, results are estimates, which are not as accurate compared with other modelling approaches. Secondly, the model does not contain an engineering assessment of spar cap retrofits. To meet design and operational performance constraints, any assessment of blade retrofits in terms of decreased LCOE must account for a variety of conflicting cost and engineering factors to arrive at an optimum retrofit solution compared with a system redesign and complete turbine replacement. Engineering studies performed concurrently with financial modelling may confirm if longer CFRP retrofitted blades can meet given wind loading, tip deflection, and power generation performance criteria, and whether increased turbulence resulting from longer retrofit blades outweighs increased power generation. Unless these are controlled as far as possible, any cost estimates will be highly uncertain. 
Any engineering study should include an assessment of how lighter blades affect nacelles and rotors designed for heavier glass blades. An assessment must also consider the environmental cost implications of complete turbine replacement compared with life extension via blade retrofits, and account for planning restrictions on the maximum allowable blade length that can be retrofitted.

Further work should explore: incorporating engineering criteria, such as wind loading, tip deflection, and edgewise fatigue limits into the model; how retrofitted blades impact engineering performance; extending the model to spar caps less than $30 \mathrm{~m}$; and investigating the applicability of the model to other turbine components. These approaches will require detailed engineering assessments and readily available cost data. Cost drivers such as inflation, variation in part complexity, and volume fraction should be investigated. As increased organizational learning reduces cost, identification and recording of human memory patterns during spar cap manufacture may enable the development of a virtual human algorithm that reinforces learning and reduces cost. Additionally, an algorithm for automatic calculation of Cost Factor Indices and Cost Scaling Feature Factors is a concept worth pursuing.

In tandem with a concurrent engineering philosophy to model different scenarios that account for specified engineering criteria covering varying wind loading regimes and power generation performance specifications, these approaches can result in an improved model to enable more accurate prediction of Levelized Cost of Energy so that spar cap retrofit design can be optimized and cost reduced.

Author Contributions: Conceptualization, J.C.; Data curation, J.C.; Formal analysis, J.C.; Investigation, J.C., T.D.; Methodology, J.C.; Project administration, A.M. and E.A.; Resources, A.M. and E.A.; Software, J.C.; Supervision, A.M. and E.A.; Validation, T.F. and P.S.; Visualization, J.C., T.D.; Writing - original draft, J.C., T.D.; Writing - review \& editing, J.C., A.M., T.F. and P.S. All authors have read and agreed to the published version of the manuscript.

Funding: This research received no external funding

Acknowledgments: The author would like to thank Alistair McIlhagger Peter Schubel for providing valuable advice and guidance. Thanks also to Tomas Flanagan of Eire Composites for useful information on composite Spar Cap manufacturing.

Conflicts of Interest: The authors declare no conflict of interest.

\section{References}

1. Ilas, A.; Ramon, P.; Rodriguez, A.; Taylor, M. Renewable Power Generation Costs in 2017; International Renewable Energy Agency: Abu Dhabi, United Arab Emirates, 2018; pp. 189-209.

2. Wind Turbine Blades: Carbon Fiber vs. Glass; Composites World: Cincinnati, OH, USA, 2012.

3. Corbyn, A.; Little, M. Fibre Glass Wind Turbine Blade Manufacturing Guide. In Engineers Without Borders (EWB -UK) E Sibol ng Agham at Teknolohiya (SIBAT_Philippines) 2008; Version 1.4 6; The Foundry A Place for Change: London, UK, 2017.

4. Presentation, Levelised Cost of Energy; US Department of Energy: Washington, DC, USA, 2012.

5. Von Weizacker, E.; Lovins, A.B.; Lovins, L.H. Factor Four: Doubling Wealth, Halving Resource Use: The new report to the Club of Rome; Earthscan: Oxfordshire, UK, 1998.

6. Dvorak, P. Repower or Refit? In That is the Question; Windpower Engineering and Development: Cleveland, OH, USA, 2014; pp. 38-42.

7. Dvorak, P. An owner's Guide to Wind Turbine Lifetime Extensions; Windpower Engineering and Development: Cleveland, OH, USA, 2014.

8. Ashby, M.; Shercliff, H.; Cebon, D. Materials: Engineering, Science, Processing E Design, 2nd ed.; Elsevier: Oxford, UK, 2010; pp. 438-441.

9. Griffith, T.; Johanns, W. Large Blade Manufacturing Cost Studies Using the Sandia Blade Manufacturing Cost Tool and Sandia 100-m Blades; Sandia National Laboratories Albuquerque: New Mexico, NM, USA, 2013.

10. Berry, D.; Lockard, S. Cost Study for Large Wind Turbine Blades: WindPACT Blade System Design Studies; Sandia National Laboratories Albuquerque: New Mexico, NM, USA, 2003.

11. Fingersh, L.; Hand, M.; Laxson, A. Wind Turbine Design Cost and Scaling Model. Natl. Renew. Energy Lab. 2006, 29, 1-43. 
12. Kooijman, H.J. Reducing Cost of Wind Energy: Opportunities to Reduce the Cost of Wind Energy; 2nd NREL Wind Energy Systems Engineering Workshop: Denver, CO, USA, 2013.

13. Schubel, P. Cost Modelling in polymer composite applications: Case study-Analysis of existing and automated manufacturing processes for a large wind turbine blade. Compos. Part B 2012, 43, 953-960. [CrossRef]

14. Schubel, P. Technical cost modelling for a generic $45 \mathrm{~m}$ wind turbine blade produced by vacuum infusion (VI). Renew. Energy 2010, 35, 183-189. [CrossRef]

15. Hutchinson, J.R.; Schubel, P.J.; Warrior, N. A cost and performance comparison of LRTM and VI for the manufacture of large wind turbine blades. Renew. Energy 2011, 36, 866-871. [CrossRef]

16. Murray, R.E.; Jenne, S.; Snowberg, D.; Berry, D.; Cousins, D. Techno- economic analysis of a megawatt-scale thermoplastic resin wind turbine blade. Renew. Energy 2019, 131, 111-119. [CrossRef]

17. Esawi, A.M.K.; Ashby, M.F. Cost estimates to guide pre-selection of processes. Mater. Des. 2003, $24,605-616$. [CrossRef]

18. Fredendall, L.D.; Gabriel, T.J. Manufacturing Complexity: A Quantitative Measure. In Proceedings of the POMS Conference, Savannah, GA, USA, 4-7 April 2003.

19. Simon, H. The architecture of complexity. Proc. Am. Philos. Soc. 1962, 106, 467-482.

20. Pippenger, N. Complexity Theory. Sci. Am. 1978, 238, 114-125. [CrossRef]

21. Cooper, W.W.; Sinha, K.K.; Sullivan, R.S. Measuring complexity in high-technology manufacturing: Indexes for evaluation. Interfaces 1992, 22, 38-48. [CrossRef]

22. Gell-Mann, M. What is complexity? Remarks on simplicity and complexity by the Nobel Prize-winning author of The Quark and the Jaguar. Complexity 1995, 1, 16-19. [CrossRef]

23. Frizelle, G. Getting the measure of complexity. Manuf. Eng. 1996, 6, 268-270.

24. Martınez-Garcıa, M.; Zhang, Y.; Gordon, T. Memory pattern identification for feedback tracking control in human machine systems. Hum. Factors 2019. [CrossRef]

25. Mesogitis, T.S.; Skordos, A.A.; Long, A.C. Uncertainty in the manufacturing of fibrous thermosetting composites: A review. Compos. Part A 2014, 57, 67-75. [CrossRef]

26. Adekunle, A.F.; Kazmer, D.O. Early Cost Estimation for Injection Moulded Parts; University of Massachusetts Amherst: Amherst, MA, USA, 1998.

27. Adekunle, A.F.; Kazmer, D.O. Modelling the Effects of Complexity on Manufacturing Costs and Time-To-Market of Plastic Injection Molded Products. In Proceedings of the Tenth Annual Conference of the Production and Operations Management Society, Charleston, SC, USA, 20-23 March 1999; University of Massachusetts Amherst: Amherst, MA, USA, 1999.

28. Adekunle, F.; Kazmer, D.; Kapoor, D. A Discussion of Design and Manufacturing Complexity; University of Massachusetts Amherst: Amherst, MA, USA, 1998.

29. Flanagan, T.; Eire Composites, an Choill Rua, Indreabhan, Co. Galway H91Y923, Ireland. Personal communication, 2016.

30. Comparative Cost Study of a $35 \mathrm{~m}$ Wind Turbine Blade Using Infusion and Prepreg Materials Technology; Wind Energy Handbook 6, Blade Cost Analysis: Prepreg vs. Infusion Material Technology; John Wiley and Sons: Hoboken, NJ, USA.

31. SparPreg ${ }^{\mathrm{TM}}$ UD Prepreg Spar Solution, Gurit. Available online: www.gurit.com (accessed on 6 August 2018).

32. Loch, C.; Tierwiesch, C. Product Development \& Concurrent Engineering. White Paper. Available online: http://bayanbox.ir/view/1335446445631086738/doc.pdf (accessed on 27 March 2020).

33. Boyle, G. Alexander. Renewable Energy: Power for a Sustainable Future, 1st ed.; Oxford University Press: Oxford, UK, 2004; pp. 265-269.

34. Mone, C.; Hand, M.; Bolinger, M.; Rand, J.; Heimiller, D.; Ho, J. 2015 Cost of Wind Energy Review; National Renewable Energy Lab. (NREL): Golden, CO, USA, 2017.

35. Renewable Energy Discount Rate Survey Results-2018; Grant Thornton: Finsbury Square, London, UK, 2019.

36. Saad, Y. Iterative Methods for Sparse Linear Systems, 2nd ed.; The Society of Industrial and Applied Mathematics: Philadelphia, PA, USA, 2003.

37. Denn, M. Chemical Engineering: An Introduction, 3rd ed.; Cambridge University Press: Cambridge, UK, 2012; pp. 80-81.

38. Lemon, R.; Bombardier Aerospace, Queen's Island, Belfast, UK. Personal communication, 2018.

39. Bloomfield, N.; Denroy Plastics Ltd., Balloo Road, Bangor, Co. Down, UK. Personal communication, 2017. 
40. Allwood, J.M.; Ashby, M.F.; Gutowski, T.G.; Worrell, E. Material efficiency: A white paper. Resour. Conserv. Recycl. 2011, 55, 362-381. [CrossRef]

41. Jensen, J.P. Routes for extending the lifetime of wind turbines. Prod. Lifetimes Environ. 2015, 152.

42. Boccard, N. Capacity Factor of wind power realized values vs estimates. Energy Policy 2009, 37, $2679-2688$. [CrossRef]

43. A Siting Specialist. Capacity Factors-Performance over time. Interview. 2015. Available online: https: //www.plateconference.org/routes-extending-lifetime-wind-turbines (accessed on 27 March 2020).

44. Staffell, I.; Green, R. How does wind performance decline with age? Renew. Energy 2013, 66, 775-786. [CrossRef]

45. Hughes, G. The Performance of Wind Farms in the United Kingdom and Denmark; Renewable Energy Foundation: London, UK, 2012.

46. Winter. How to Operate and Maintain Wind Assets; McKinsey \& Company: Washington, DC, USA, 2008; pp. 8-14.

47. Maxey, K. Wind Turbine Retrofits Increase Their Efficiency; Engineering.com: Mississauga, ON, Canada, 29 May 2014.

48. Roth-Johnson, P. Aero-Structural Design Investigations for Biplane Wind Turbine Blades. Ph.D Thesis, University of California Los Angeles, Los Angeles, CA, USA, 2014.

49. Wu, W.-H.; Young, W.-B. Structural Analysis and Design of the Composite Wind Turbine Blade. Appl. Compos. Mater. 2011, 19, 247-257. [CrossRef]

50. Singh, V.K.; Thomas, T.T.; Warudkar, V. Structural Design of a Wind Turbine Blade: A Review. Int. J. ChemTech Res. 2013, 5, 2443-2448.

51. Sharma, R.N.; Simha, T.G.A.; Rao, K.P.; Kumar, R.J.V.V. Carbon Composites are Becoming Effective and Cost Competitive; White Paper; Infosys: Bengaluru, India, 2018.

52. Attias, K.; Ladany, S.P. Optimal Layout for Wind Turbine Farms. In Wind Energy Applications; World Renewable Energy Congress: Linkoping, Sweden, 2011.

53. Ortegon, K.; Nies, L.F.; Sutherland, J.W. The impact of maintenance and technology change on remanufacturing as a recovery alternative for used wind turbines. Procedia CIRP 2014, 15, 182-188. [CrossRef]

(C) 2020 by the authors. Licensee MDPI, Basel, Switzerland. This article is an open access article distributed under the terms and conditions of the Creative Commons Attribution (CC BY) license (http://creativecommons.org/licenses/by/4.0/). 